\title{
EL INICIO DEL COLECCIONISMO ILUSTRADO DE MOMIAS GUANCHES DURANTE EL SIGLO XVIII. BARRANCO DE ERQUES Y ACANTILADO DE MARTIÁNEZ (TENERIFE, ISLAS CANARIAS)
}

\author{
Alfredo Mederos Martín* \\ Universidad Autónoma de Madrid \\ Gabriel Escribano Cobo** \\ Universidad de La Laguna
}

\section{RESUMEN}

Para los siglos XVI y XVII sólo tenemos referencias puntuales a la visita de una o varias cuevas con momias guanches por Thomas Nichols ca. 1558 y Evan Pieugh en 1646, ambas en las inmediaciones de Candelaria y Güímar. La primera exploración con interés coleccionista se produjo en 1764 en el barranco de Erques por Luis Román. Al menos se recuperaron tres momias, una de las cuales se envió a Madrid y dos años después, en 1766, fue entregada a la colección de la Real Biblioteca. Un segundo grupo de momias salió en 1772, una o dos llegaron a París y otras tres a Londres, de las cuales una pasó al Museo Británico y otra al Trinity College en Cambridge.

PALABRAS ClaVe: momias, guanches, siglo XVIII, Ilustración, coleccionismo de antigüedades.

\section{THE BEGINNING OF THE ILLUSTRATED MUMMIES COLLECTING IN TENERIFE DURING THE XVII ${ }^{\text {th }}$ CENTURY. ERQUES RAVINE AND MARTIÁNEZ CLIFF}

\section{Abstract}

For the sixteenth and seventeenth centuries we only have specific references to the visit of one or several caves with guanche mummies by Thomas Nichols ca. 1558 and Evan Pieugh in 1646, both in the vicinity of Candelaria and Güímar. The first exploration with a collector interest was in 1764 in a cave in the Erques ravine by Luis Román. At least 3 mummies were recovered, one of them was sent to Madrid and two years later, in 1766, was delivered to the collection of the Royal Library. A second group of mummies was send in 1772, one or two arrived in Paris and three others to London, of which one went to the British Museum and another to the Trinity College in Cambridge.

KEYwORDs: mummies, guanche, eighteenth century, Illustration, antique collecting. 


\section{PRIMERAS REFERENCIAS DEL SIGLO XVI}

Los datos en las fuentes para el siglo XVI son breves, pero algunas nos indican hechos contemporáneos que ya no se trata de referencias orales sobre los guanches de antes de la conquista. Aunque todavía no había empezado un expolio sistemático por el coleccionismo de cráneos y momias en cuevas, aún los descendientes trataban de proteger los lugares donde estaban enterrados, manteniendo en secreto sus emplazamientos, «en las cimas más altas hay otras cuevas y cavernas en donde sepultaban sus muertos [...] y los embalsamaban [...] Todavía ahora los que proceden de ellos se ofenden y afrentan mucho si van a tocarlos o si algún travieso va a tirar alguno de los cuerpos muertos y mirlados de la peña abajo»'

No obstante, algunos viajeros extranjeros ya habían logrado acceder a algunas de estas cuevas. Thomas Nichols había estado viviendo en Tenerife desde 1555, con 24 años, hasta 1563, ya con 31 años, desplazándose también a menudo a La Palma, representando en ambas islas los intereses de comerciantes ingleses para la compra de azúcar y su posterior envío a la Península, Flandes e Inglaterra. La visita, siendo aún joven, quizás aprovechase algún viaje al sur de la isla pues menciona ante la Inquisición en 1560 «[h]aver ido a N.S. de Candelaria, de romería» ${ }^{2}$. Nichols aportará los primeros datos de primera mano: «He visto cuevas de 300 de estos cadáveres reunidos; la carne estaba reseca, y el cuerpo se quedaba tan ligero como un pergamino" ${ }^{3}$.

Los protocolos notariales indican un dato importante: el barranco de Erques, límite de la costa de Agache entre Güímar y Fasnia, recibía alternativamente el nombre de barranco de los Muertos, lo que impulsará futuras visitas. Según un protocolo de 1579, «Dice que tiene en Fasnia, en Agache, donde dicen el barranco de los Muertos, 30 fanegas de tierra» ${ }^{4}$. En los Cuadernos de Citas de Anchieta tenemos dos referencias más procedentes de protocolos notariales, «desde el barranco de los Muertos hasta el Archenche [barranco cerca de Icor en Arico], ante Juan del Cas-

* Departamento de Prehistoria y Arqueología de la Universidad Autónoma de Madrid. Facultad de Filosofía y Letras. Campus de Cantoblanco. 28049 Madrid. España. Correo electrónico: alfredo.mederos@uam.es, https://orcid.org/0000-0002-0036-7940.

** Profesor de Instituto de Enseńanzas Medias. Programa de Doctorado. Departamento de Prehistoria, Historia Antigua y Antropología. Universidad de La Laguna. Avenida Trinidad, 39. 38204. La Laguna. Tenerife. España. Correo electrónico: escribanocobogabriel@gmail.com.

${ }^{1}$ Frutuoso, G. (1964 [1584-90]): Saudades da Terra. En E. Serra Ràfols, J. Régulo y S. Pestana (eds.): Las Islas Canarias de 'Saudades da Terra'. La Laguna, p. 105.

${ }^{2}$ Cioranescu, A. (1963): Thomas Nichols. Mercader de azúcar, hispanista y hereje. La Laguna, pp. 15, 32, 35 y 56.

${ }_{3}$ Nichols, Th. (1963 [1583]): Descripción de las Islas Afortunadas. En A. Cioranescu (ed.): Thomas Nichols. Mercader de azúcar, hispanista y hereje. La Laguna, pp. 116-117.

${ }^{4}$ Urtarte, S. De (2000 [1573-83]): El Valle de Güimar en el siglo XVI. Protocolos de Sancho de Urtarte. En M.A. Gómez Gómez (ed.). Tenerife, p. 302. 
tillo [el] 2 de octubre de 1573 [...] en Agache»5. En otro protocolo de 1554, «de la parte de Agache, digo, de Candelaria, el barranco de los Muertos, por la vereda; de la parte de Abona, el barranco de Timijar [costa de Agache]». También es mencionado como barranco de Erques, «en Agache, que lindan, de una parte de hacia esta ciudad, el barranco de Erques y, de la otra parte, el barranco de Tenejo [barranco de los Palmeros, Fasnia] $]^{6} \%$.

El texto de Nichols pudo conocerlo Sedeño ${ }^{7}$, pues menciona que «otros hauía mirlados que no les faltaban cauellos ni dientes, encerrados dentro de cuebas, puestos en pie arrimados i otros sentados, i mujeres con niños a los pechos, todos mui enjutitos que casi se les conocían las faiciones [...]. Y ai cuebas llenas destas osamentas que es admiración». Pero también sugiere que debía haber visto personalmente algún cuerpo. Esta referencia la reproduce de forma muy similar Marín de Cubas ${ }^{8}$ : «Tenían grandes rumazones de cuerpos mirlados tan enjutos que parecian de madera, y forrados en pieles havia mugeres con los nińos a el pecho enjutos con todas sus perfecciones, que podian conoserse, y sin faltarles cavellos antes los tenian rubios largos y fuertes».

\section{EL INICIO DEL TRÁFICO DE MOMIAS EN EL SIGLO XVII}

Dos datos sugieren que el tráfico de cuerpos momificados comenzó quizás desde finales del siglo xvi y continuó durante el siglo xvir. En la relación de Purchas ${ }^{9}$ menciona: «Yo mismo vi dos de estos cuerpos en Londres», enviados junto a los cargamentos habituales de vino canario. Por otra parte, el licenciado Francisco López de Ulloa ${ }^{10}$ menciona el hallazgo probablemente en Gran Canaria, porque allí residió con seguridad hasta julio de $1643^{11}$, y la exhibición de otra momia, pues «el año de 1644 vi traer un cuerpo de aquellos entero, sin faltarle ninguna parte del seco", falleciendo en Madrid en septiembre de 1668, donde era el administrador de los bienes del tercer marqués de Castelo Rodrigo, Francisco de Moura Corte-Real, muerto en 1675 .

5 Anchieta y Alarcón, J. de (2017 [1735-67]): Cuaderno de citas. I-V. En D. García Pulido (ed.). Tenerife, p. 76, GHI-172.

${ }^{6}$ Anchieta y Alarcón, J. de, opus cit., n. ${ }^{\circ}$ 5, p. 123 MNO-483.

7 SEDEÑo, A. (1978 [1507-1640]): Brebe resumen y historia muy verdadera de la conquista de Canaria. En F. Morales Padrón (ed.): Canarias: crónicas de su conquista. Sevilla-Las Palmas, p. 376.

${ }^{8}$ Marín de Cubas, T. (1986 [1694]): Historia de las siete islas de Canaria. En A. de Juan Casañas, M. ${ }^{a}$ Régulo y J. Cuenca (eds.). Las Palmas, p. 279.

9 Purchas, S. (1613): Purchas his Pilgrimage or Relations of the World and the Relations of the World and the Religions Observed in all Ages and Places Discovered from the Creation unto this Present. London, p. 598.

${ }^{10}$ López de Ulloa, F. (1978 [1646]): Historia de la conquista de las siete yslas de Canarias. En F. Morales Padrón (ed.): Canarias: crónicas de su conquista. Sevilla-Las Palmas, p. 316.

${ }^{11}$ Millares Carlo, A., Hernández Suárez, M., Vizcaya, A. y Millares Sal, A. (1987): Biobibliografía de escritores canarios (siglos XVI, XVII y XVIII). V. J-P. Madrid-Las Palmas, p. 85. 
En Gran Canaria contamos con una referencia interesante sobre descubrimientos vinculados al reaprovechamiento de maderas de calidad en La Isleta, cerca de Las Palmas, "por codicia de palos de buena madera en las Isletas han descubierto muchas cassas i sepulchros llenos de estos mirlados» ${ }^{12}$.

La referencia más importante la recoge Thomas Sprat, formado en Oxford, dos años antes de ser nombrado canónigo de la abadía de Westminster, quien la incluyó dentro de su Historia de la Real Sociedad de Londres. Después de la descripción de una ascensión al pico del Teide por seis comerciantes británicos hacia el 20 de agosto de 1646, hace referencia a la visita de una o varias cuevas con momias guanches por parte de un médico galés, Evan Pieugh, residente en La Laguna. Un importante comerciante, Marmaduke Rawdon, lo había traído a Tenerife para que trabajase como médico de la colonia británica, residiendo unos 16 años en la isla, aproximadamente entre la segunda quincena de abril de 1639 y finales de noviembre de 1655, durante 17 ańos $^{13}$. En 1655 ambos abandonaron la isla por las crecientes tensiones bélicas con la Inglaterra de Cromwell, que implicó una declaración formal de la guerra desde octubre de 1655, con un embargo de todos los barcos ingleses y de los bienes de los ciudadanos británicos.

Apenas dos semanas después de la ascensión al Teide, el 3 de septiembre de 1646, Pieugh "emprendió una excursión desde Güímar (un pueblo habitado en su mayor parte por los descendientes de los primitivos guanches) en compañía de algunos naturales, a ver sus cuevas y los cuerpos enterrados en ellos. Es éste un favor que nunca conceden o que lo hacen en muy raras ocasiones (puesto que sienten gran veneración por los cuerpos de los antepasados, y asimismo porque están en contra de que se moleste de alguna forma a los muertos); pero él había hecho varias curas gratuitas entre ellos» ${ }^{14}$. La mención tanto en la visita al Teide a un volcán que explotó en La Palma «hace doce años», el volcán Martín del 1 de octubre a 18 de diciembre de 1646, como en la excusión a Güímar «de hace aproximadamente doce años ${ }^{15}$, sugiere que ambos hechos se realizaron el mismo año, aunque la visita a Güímar habitualmente se ubica hacia 1658 , la fecha de redacción del texto ${ }^{16}$, cuando ya Pieugh ya no residía en Tenerife.

Esta descripción sugiere un procedimiento parecido a la visita realizada hacia 1560 por Thomas Nichols, quien debió salir también desde Güímar, quizás

12 Gómez Escudero, P. (1978 [1639-1700]): Libro Segundo. Prosigue la conquista de Canaria. En F. Morales Padrón (ed.): Canarias: crónicas de su conquista. Sevilla-Las Palmas, p. 431.

${ }_{13}$ Davies, R. (ed.) (1863): The Life of Marmaduke Rawdon of York or Marmaduke Rawdon, the Second of that Name. London; Guerra Cabrera, J.C. (1994): Biografia de Marmaduke Rawdon. Un mercader inglés en Tenerife en el siglo XVII. Tenerife, pp. 49, 60-62 n. 79.

14 Sprat, T. (2006 [1667]): «Relación del Pico de Tenerife, que se debe a unos estimables comerciantes y hombres dignos de crédito que subieron a la cima». F.J. Castillo (ed.): La isla del Pico en las relaciones de los primeros viajeros ingleses. Sevilla-Tenerife, pp. 84-85.

15 Sprat, T., opus cit., n. ${ }^{\circ} 14$, pp. 82 y 84.

16 Castillo, F.J. en Sprat, T., opus cit., n. ${ }^{\circ}$ 13, p. 71; Méndez Rodríguez, D.M. (2014): Momias, xaxos y mirlados. Las narraciones sobre el embalsamamiento de los aborigenes de las Islas Canarias (1482-1803). La Laguna, p. 90. 


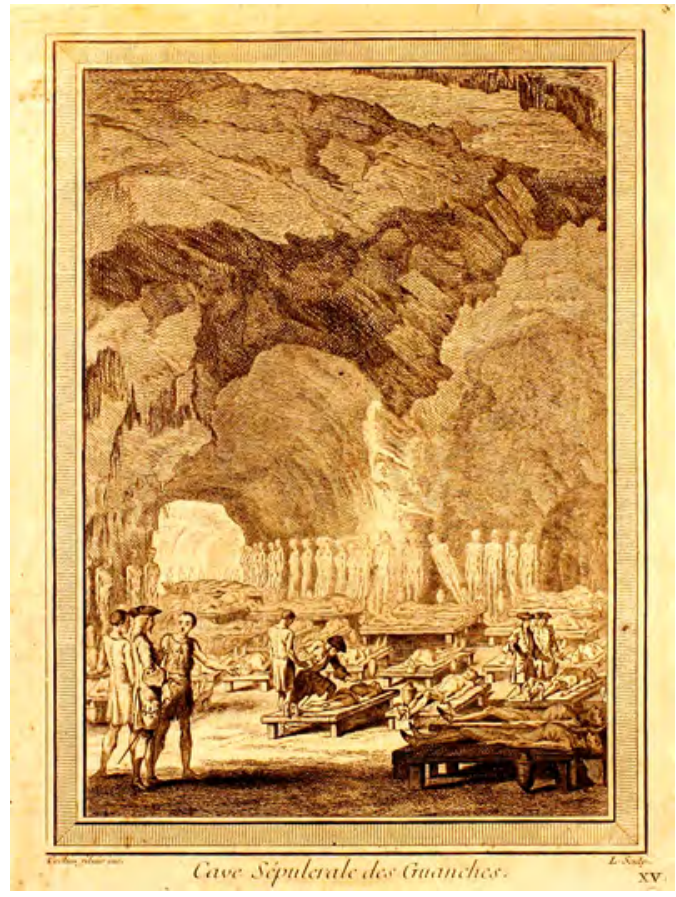

Fig. 1. Grabado imaginario de Nicolas Cochin sobre una cueva funeraria guanche en Prévost (1746), a partir de la descripción de Sprat (1667).

coincidiendo durante su estancia por la fiesta de La Candelaria, que se celebra el 15 de agosto. La distancia desde Candelaria al barranco de Erques son $27 \mathrm{~km}$, que se reducen a $15,7 \mathrm{~km}$ desde el pueblo de Güímar.

La descripción de la cueva es muy genérica y coincide con la aportada por Nichols, «el vio cerca de tres o cuatrocientos [cuerpos] en varias cuevas; algunos estaban de pie, otros reposaban en lechos de madera ${ }^{17}$, que cabe correlacionar con la cueva con «300 de estos cadáveres», donde los «arrimaban a una pared, estando erguido sobre sus pies» ${ }^{18}$. También se asocia con una referencia de Frutuoso ${ }^{19}$ sobre la existencia de cuevas donde podían vivir 200 o 300 personas, lo que sugiere que todos son cálculos aproximados y queda la duda si se trataba de una única cueva según Nichols o varias según Pieugh, aunque la primera opción es la más lógica (fig. 1).

Respecto a las momias, Pieugh menciona que «dichos cuerpos están envueltos en pieles de cabra con cuerdas de lo mismo, con mucho esmero, particularmente en

${ }^{17}$ Sprat, T., opus cit., n. ${ }^{\circ} 14$, p. 85.

${ }_{18}$ Nichols, Th., opus cit., n. ${ }^{\circ}$ 3, pp. 116-117.

${ }^{19}$ Frutuoso, G., opus cit., n. ${ }^{\circ}$ 1, p. 105. 
las exactas y cuidadosas costuras, y las pieles se colocan adheridas al cuerpo, adoptando la forma de éste; la mayor parte de los cuerpos están enteros, los ojos cerrados, con pelo en la cabeza, orejas, nariz, dientes, labios, barba, todo muy conservado, sólo que un poco encogido y descolorido, por ejemplo las partes pudendas de ambos sexos [...]. Estos cuerpos son muy ligeros, como si estuvieran hechos de paja, y en algunas extremidades destrozadas observó los nervios y los tendones, y también nítidamente algunos fragmentos de las venas y las arterias ${ }^{20}$.

El Dr. Pieugh trató de enterarse del número de cuevas en la isla que podían tener momias, entrevistándose con diversas personas de avanzada edad. «Estos ancianos le contaron que tenían unas veinte cuevas con sus reyes y nobles, además de las familias de éstos, que todos desconocían salvo ellos mismos, paraderos que ellos nunca dirían donde están $»^{21}$. El más anciano, quien le comentó que tenía la muy dudosa edad de 110 años, le explicó el procedimiento de tratamiento de los cuerpos, quizás algo distorsionado por la tradición oral, «primeramente evisceraban los cuerpos y cuando se trataba de los pobres, para ahorrar gastos, le extraían el cerebro, y los cosían en pieles con pelo, mientras que los ricos (como se dijo antes) se colocaban en pieles cosidas tan fina y primorosamente que permanecen hasta hoy muy poco arrugadas y bien conservadas [...] el cuerpo, secándolo al sol en el verano, $y$ en hornos en el invierno $»^{22}$.

\section{GEORGE GLAS Y EL INICIO DEL COLECCIONISMO ILUSTRADO DE MOMIAS (1761)}

Durante la primera mitad del siglo XviII carecemos de menciones precisas sobre momias que se reanudan a mediados de la centuria. La primera es una referencia personal de Viera y Clavijo ${ }^{23}$. «La duración de estos cadáveres, que los guanches llamaban xaxos, es tan asombrosa, que todavía se encuentran incorruptos en las grutas de Tenerife. [Yo ví el año de 1752 el de una mujer que conservaba hasta las uñas, los ojos y los cabellos rubios, atados con una correa]». La referencia al hallazgo es aún más precisa en Anchieta: «[el] martes 18 de julio de 1752 me dijo [...] que en una cueva de La Orotava se había hallado una guancha aún entera, con sus pieles toda cosida y hasta el pelo atado con una correíta. Fue cierto, sobre Martiánez, en unas cuevas que allí hay. Le dio gana a uno de subir a ver y halló muchos cuerpos mirlados y sacó uno que llevó al Puerto y Villa y había mucha leña de sabina. Dijeron que mucha sacó y mucha quedaba ${ }^{24}$. Debe tratarse de las cuevas funera-

${ }^{20}$ Sprat, T., opus cit., n. ${ }^{\circ} 14$, pp. 85-86.

${ }^{21}$ Sprat, T., opus cit., n. ${ }^{\circ} 14$, pp. 88-89.

22 SPrat, T., opus cit., n. ${ }^{\circ} 14$, p. 88.

23 Viera y Clavijo, J. De (1967-71 [1776-83]): Noticias de la Historia General de las Islas de Canaria. I. En A. Cioranescu (ed.). Tenerife, p. 172.

24 Anchieta y Alarcón, J. de (2011 [1722-67]): Diario. II. En D. García Pulido (ed.). Tenerife, p. 40 . 


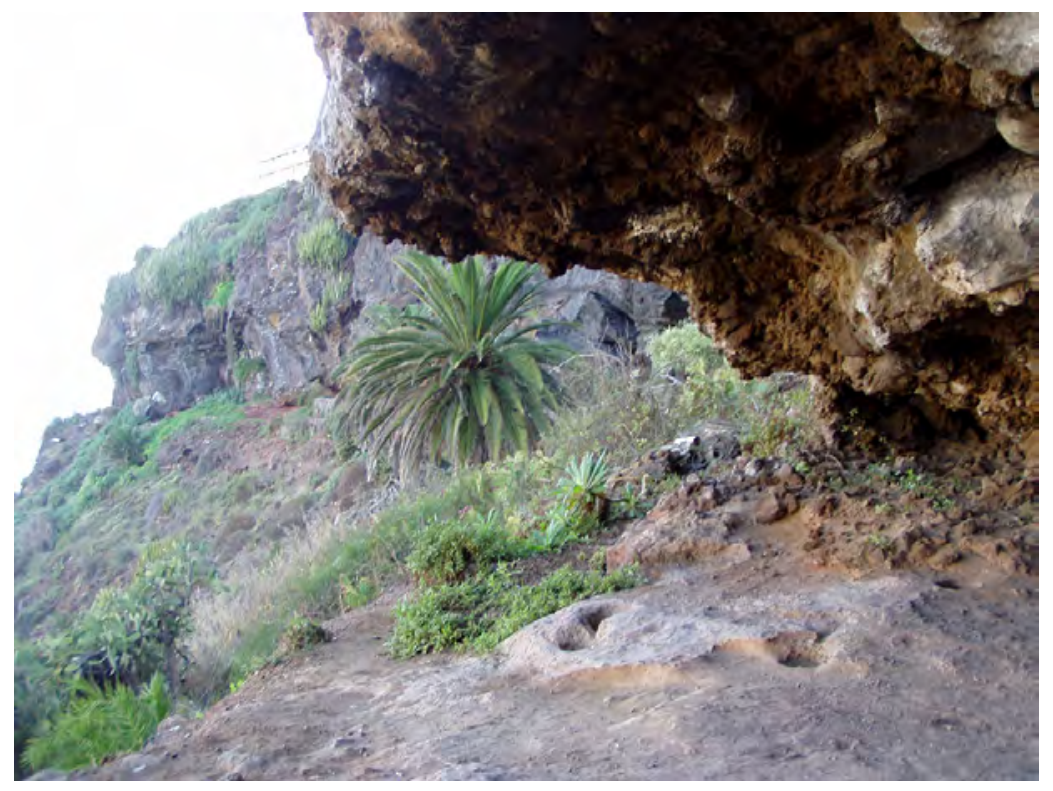

Fig. 2. Vista del acantilado de Martiánez (Puerto de la Cruz) desde la cueva v con cazoletas, donde aparecieron una o dos momias en 1752 .

rias II o IV del acantilado de Martiánez o de Martín Yanes (Puerto de la Cruz)25. El motivo real del descubrimiento, como ya había sucedido en Gran Canaria durante el siglo XVII ${ }^{26}$, era la búsqueda de madera de calidad que se utilizaba en las cuevas para preparar camastros vegetales donde se depositaban los cuerpos y no entrasen en contacto con el suelo. Ya había un interés entre la población, como señala Anchieta ${ }^{27}$, pues la momia la «enseñó en el Puerto [de la Cruz] y trajeron a la Villa [de la Orotava] a enseñar y sacaba sus reales del que lo quería ver» (fig. 2).

No cabe descartar que otra referencia sobre dos momias descubiertas mencionadas por el escocés George Glas ${ }^{28}$ sea la misma que la anterior de 1752, pues solía hacer escala en el Puerto de la Cruz. "No hace muchos años, dos de estos cuerpos embalsamados fueron sacados de una cueva; estaban enteros y tan ligeros como

${ }^{25}$ Mederos, A. y Escribano, G. (2008): «Prospección arqueológica del litoral del Menceyato de Taoro. Municipios de Los Realejos, Puerto de la Cruz y La Orotava (Tenerife)». Canarias Arqueológica (Eres), 16, p. 110.

${ }^{26}$ Gómez Escudero, P., opus cit., n. ${ }^{\circ}$ 12, p. 431.

27 Anchieta y Alarcón, J. de, opus cit., n. ${ }^{\circ}$ 5, p. 17 GHI-21.

${ }^{28}$ Glas, G. (2010 [1764]): La Historia del Descubrimiento y de la Conquista de las Islas Canarias: Traducida de un Manuscrito Español, recientemente descubierto en la Isla de La Palma. Con un Informe sobre el Origen de los Antiguos Habitantes -1764-. P.N. Leal Cruz (ed.). La Laguna, p. 175. 
el corcho, pero completamente frescos y sin ningún mal olor. Sus cabellos, dientes $y$ vestidos estaban enteros y frescos».

A mediados del siglo XVIII ya se observa el inicio de un interés por parte de algunos de estos viajeros, que comenzaron a contratar a escaladores que recogían el liquen de la orchilla de las paredes de los barrancos y zonas acantiladas para buscar momias e incorporarlas a colecciones particulares. El primer caso que tenemos constatado con seguridad fue por George Glas, por entonces con 34 años, que había realizado regulares estancias como marino en varias de las Islas Canarias antes de intentar fundar una factoría de pesquerías en Guader (Marruecos), junto a la antigua torre de Santa Cruz de Mar Pequeña, que denominó Port Hillsborough en honor del earl o conde de Hillsborough, entonces presidente del comité de comercio y plantaciones. Sin embargo, fue a conseguir provisiones a Lanzarote en 1764, dirigiéndose después a Tenerife después de hacer escala en Gran Canaria. Una vez que arribó fue detenido al desembarcar, permaneciendo encarcelado por las autoridades españolas en Santa Cruz de Tenerife desde el 29 de noviembre de 1764 hasta el 15 de octubre de $1765^{29}$. Entre tanto la colonia sufrió el asalto por los indígenas del navío inglés con los hombres de Glas en febrero de 1765, que incendiaron y dieron muerte a varios. Pudieron escapar en dos chalupas doce ingleses, su mujer y su hija, alcanzando Gran Canaria el 5 de abril ${ }^{30}$. Liberado, regresó a Inglaterra partiendo del Puerto de la Cruz en el mes de noviembre de 1765, pero la tripulación del bergantín Earl de Sandwich se sublevó al sur de Irlanda y asesinaron al capitán Jonathan Cochran y Glas el 30 de noviembre, mientras su mujer Elizabeth y su hija Catherine, de 12 años, fueron tiradas por la borda ${ }^{31}$.

La primera búsqueda consciente de momias se produjo cuando arribó George Glas al Puerto de la Cruz, primero el 9 de febrero de 1759 con el bergantín Depsy, después de haber sufrido su tripulación una enfermedad de fiebres en la costa de Gambia por la que murieron 15 marinos, sobreviviendo sólo Glas y otros siete marinos también afectados, vendiendo un esclavo que traía de Cabo Verde y permaneciendo en el Puerto de la Cruz en casa del vicecónsul inglés al menos hasta el 9 de marzo ${ }^{32}$.

Volvió a hacer escala en Tenerife el 1 de agosto de 1761, pues compró en el Puerto de la Cruz el bergantín El Santísimo Cristo y Nuestra Señora del Carmen ${ }^{33}$, y un mes después, a inicios de septiembre, sabemos que ascendió al Teide saliendo

${ }^{29}$ Guerra y Peña, L.A. De la (2002 [1760-91]): Memorias. Tenerife en la segunda mitad del siglo XVIII. E. Roméu Palazuelos (ed.). Madrid-Las Palmas, p. 165; Rodríguez Yanes, J.M. (2000): "George Glas y su prisión en Canarias (1764-1765), un asunto de estado». Revista de Historia Canaria, 182, pp. 184 y 197.

30 Viera y Clavijo, J. de, opus cit., n. ${ }^{\circ} 23$, p. 615; Rodríguez Yanes, J.M., opus cit., n. ${ }^{\circ} 26$, p. 191.

31 Monod, T. (1976): «Notes sur George Glas (1725-1765), fondateur de Port Hillsborough (Sahara marocain)». Anuario de Estudios Atlánticos, 22, pp. 417, 468-474, fig. 12.

32 Rodríguez Yanes, J.M., opus cit., n. ${ }^{\circ} 29$, pp. 178-181.

33 Rodríguez Yanes, J.M., opus cit., n. ${ }^{\circ} 29$, p. 182. 
desde el Puerto de la Cruz ${ }^{34}$, donde seguramente había estado residiendo, esta vez con mejores condiciones físicas que en 1759.

Es probable que durante la segunda estancia fuera cuando hiciera el encargo para localizar una momia, quizás explorando la zona del acantilado de Martiánez del Puerto de la Cruz donde hacía pocos años se habían encontrado restos momificados. «Hace dos años aproximadamente contraté a algunos de los naturales de Tenerife a que entraran en una de estas cuevas (que era casi inaccesible) para ver si podían encontrar a algunos de estos cadáveres; me trajeron algunos huesos, y trozos de vestidos de piel de cabra, etc, y una calavera con pelo, que era negro y lacio; los vestidos estaban completamente enteros y conservaban todavía el pelow ${ }^{35}$. La fecha de 1761 puede fijarse bien porque en su libro se señala la muerte «hace como un año " ${ }^{36}$, el 26 de noviembre de 1762, de Cristóbal del Hoyo-Solórzano y Sotomayor, marqués de San Andrés y vizconde de Buen Paso, y la búsqueda de la momia fue «hace dos ańos».

\section{EL REDESCUBRIMIENTO DE LA CUEVA CON MOMIAS DEL BARRANCO DE ERQUES (1764)}

No obstante, este nuevo espíritu coleccionista también impregnaba a las élites locales, como fue el caso de Gabriel Román Manrique de Lara de Reguilón. Nacido en La Laguna el 16 de noviembre de 1720, con lo que tenía 43 ańos cuando se volvió a visitar la cueva de Erques, fue teniente coronel del regimiento de milicias de Güímar y Candelaria desde 1755, caballero del hábito de Santiago y regidor perpetuo de Tenerife. Casado con Anastasia Machado Fiesco, falleció en La Laguna el 30 de octubre de $1783^{37}$. Se conserva un retrato suyo de 1771 con su segundo hijo, Sixto Román y Machado, de cinco ańos, realizado por el pintor José Rodríguez de la Oliva, y otro de su mujer Anastasia con su única hija, María Ana Román y Machado Fiesco, que quizás pudo realizarse pocos ańos antes ${ }^{38}$ (figs. 3a-3b).

Durante la primavera, antes de julio de 1764, se debió volver a visitar la misma cueva que ya había sido objeto de exploraciones por Nichols hacia 1558 y Pieugh en 1646. Diversos datos parecen coincidir: la visita con habitantes «de Güímar», las dimensiones de la cueva o la presencia de «muchos cuerpos de guanches» junto a las paredes en «andamios [...] de palos de sabina». El hallazgo se comentó

${ }^{34}$ Glas, G., (1982 [1764]): Descripción de las Islas Canarias 1764. C. Aznar (ed.). La Laguna, p. 83.

${ }^{35}$ Glas, G., opus cit., n. ${ }^{\circ} 28$, p. 175.

${ }^{36}$ Glas, G., opus cit., n. ${ }^{\circ} 34$, p. 159.

37 Fernández de Béthencourt, F. (1952 [1878-86]): Nobiliario de Canarias. II. J. La Laguna, pp. 392 y 395; PAz SÁNCHez, M. DE (2013): «Edición, introducción y notas». J. de Viera y Clavijo, Homenaje a Carlos III. Tenerife, p. 77 n. 20.

38 Fraga González, C. (1983): Escultura y pintura de José Rodríguez de la Oliva (16951777). Tenerife, pp. 74-76, lám. 14. 


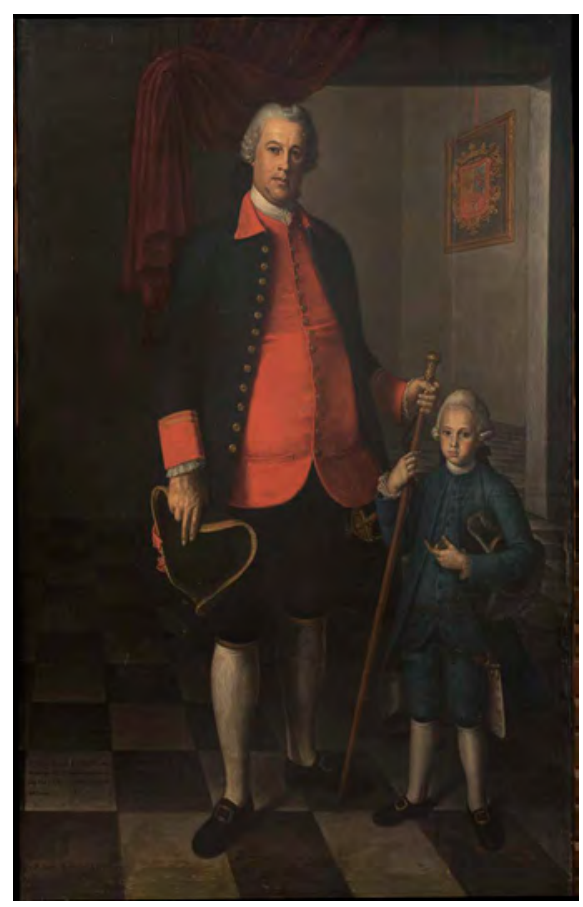

Fig. 3a. Retrato de Gabriel Román Manrique de Lara con su segundo hijo, Sixto Román y Machado, por José Rodríguez de la Oliva (1771). Colección particular, Tenerife (Lorenzo Lima ed. 2018: 98 fig. 96).

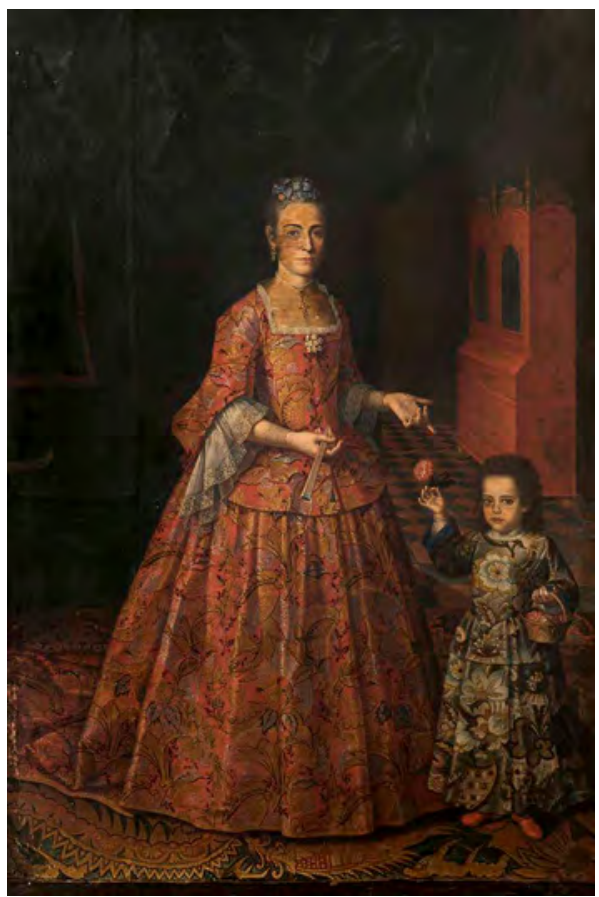

Fig. 3b. Retrato de su mujer, Anastasia Machado Fiesco, con su única hija, María Ana Román y Machado Fiesco, por José Rodríguez de la Oliva (1771). Colección particular,

Tenerife (Lorenzo Lima ed. 2018: 90 fig. 93).

pocos meses después en La Laguna en la casa del teniente coronel Agustín Gabriel del Castillo y Ruiz de Vergara, corregidor y capitán de guerra de Tenerife entre 1763-69. "Guanches: ayer miércoles 17 de octubre de 1764 años, estando en casa del corregidor don Agustín del Castillo, y allí don Gabriel Román, se habló sobre guanches y que en las cuevas de..., en un risco muy alto, está una cueva en la habiendo ido con otros de Güímar don Luis Román, entraron en una cueva muy grande, la que llenaron de hachos de tea o de fuego (mas de doscientos) para ver bien lo que estaba dentro y hallaron muchos cuerpos de guanches, que allí debía de ser el lugar del entierro, y que estaba alrededor, a los lados de la cueva, muchos como andamios a modo de tiendas, de palos de sabina y en aquellos andamios estaban los cuerpos de los guanches tendidos, mirlados, y para otro lado como que se había caído un pedazo de cueva y entullado muchos, que unos ya estaban casi todo en huesos, otros a medio cuerpo descubiertos los huesos y lo otro aun entre lo mortaja, y algunos aún enteros en su mortaja y que sacaron algunos, que uno hallaron envuelto en nueve mortajas, todas de cuero, los cueros muy bien cosidos unos con otros como una sábana y, allí, 
envuelto el cuerpo y después la punta de fuera cosida por un lado de alto abajo [...] así era la costura y quedaba el cuerpo allí sujeto dentro de la costura. Uno de estos cuerpos, el más perfeccionado que ni aun la punta de la nariz le faltaba, lo mandaron a un cajón bien ajustado con lana a don Francisco Machado, regidor, hijo de don Álvaro Yanes Machado y cuñado del dicho don Gabriel [Román], que está en la Corte, para que se vea cómo hay cuerpos conservados al cabo de tantos años. Era de la estatura de cualquier hombre y así dicen que eran los que están en dicha cueva, que son muchísimos. Otro con gran instancia llevó a Francia un capitán de navío francés; otro llevó a España don Lorenzo Vázquez Mondragón, administrador de los estancos; y otro que dicho don Gabriel Román tiene en su casa, que dicho miércoles, ayer tarde, a las cinco, me dijo que viniera con él y lo vería, y habiendo venido sacó de un cajón un cuerpo de un guanche mirlado todo él, aún entero que ni una uńa le falta, con todo su cabello negro, como que lo tenía corto, y su montera de pelleja, el cuerpo para fuera; las manos abiertas una encima de otra, puestas sobre el empeine, vueltas adentro, los dedos muy estirados y los de los pies también, y como que habían sido atados uno con otro divididos, y en pies y manos. El cuero todo él aún en el cuerpo, sin faltarle nada y las carnes muy secas, ni más ni menos que las carnes de un hombre muy viejo, aunque estas, más pardas y secas; lo mismo las espaldas, no como esqueleto cubierto de piel, sino como una tocineta seca, así es todo el cuerpo del guanche y de la estatura de cualquier hombre y los nervios aún fuertes porque, al tenderlo en el cajón, aun se hace fuerte el no poderlo doblegar. Estaba este guanche amortajado en unas pieles cosidas unas con otras, no zaleas sino cuero como curtido, como gamuzas no zaleas, que se le cae el pelo, sino cueros ni más ni menos que curtidos y algo amarillos, muy ajustadamente cosidos y del tamańo de una sábana pequeña [...] los dedos de los pies desunidos y como que un pie sobre otro, le ataron todos los dedos unos con otros; los brazos [...] de tener la palma de la mano sobre el empeine [...] unos tienen las manos así y otros tendidos los brazos al cuadril y la mano abierta y vuelta al cuadril, y que así fue el que fue a España, a [Francisco] Machado [...] el que fue a España tenía el miembro viril del cumplido de más de media cuarta y aún del grueso de un pulgar de los más gruesos, los compañones aún colgando y como secos allí dentro. Este que está y me mostró don Gabriel Román se le muestran por detrás, por entre las nalgas, aún tan grandes colgado mayor que una nuez grande [...]. En la cueva de donde sacaron el que tiene don Gabriel Román y fueron a Espańa, me dijo don Gabriel y el corregidor que se hallaron un cántaro con su asa de barro, muy bien hecho y muy bruñido, a modo de cuarterón, y también me dijeron [que] había platos de barro y otras cosas. Dijo el corregidor [...] que la primera mortaja era de estas pieles agamuzadas como digo, pero que los demás afuera eran pieles con lana y otras de pelos y que la lana y pelos estaban vuelta adentro y fuertes, que aunque se halaran por ella no se arrancaba como si fuera y estuvieran acabadas de quitar de la res $»^{39}$.

39 Anchieta y Alarcón, J. de, opus cit., n. ${ }^{\circ}$ 5, pp. 15-17, GHI-21. 
La momia que permaneció en Tenerife continuaba siendo propiedad de Gabriel Román en 1770. «Se conservan aún algunas Cuevas llenas de cadáveres de Guanches. En 3 de Enero de 1770 vi uno en Casa del Theniente Coronel Don Gabriel Román, que estaba entero, i aún con su cabello i dientes» ${ }^{40}$. La momia estaba en su residencia familiar de la calle San Agustín de La Laguna, reformada en 1866, que pasó desde 1925 a ser el lugar donde se impartían los estudios de Aparejadores e Ingeniero técnico y desde 1994 es sede de la Universidad Nacional de Educación a Distancia.

La visita a la cueva en 1764 figura en la Historia de Canarias de Viera y Clavijo aportando nuevos datos como la mención al topónimo de «barranco de Herque, entre Arico y Güímar». En el libro de Viera comienza la exageración sobre el número de los cuerpos depositados, pues se considera que alcanzaban un millar. "Al tiempo que se escriben estas Noticias, se acaba de descubrir un panteón excelente [...]. La cueva, aunque de una entrada sumamente difícil, es en lo interior alta, capaz y acompańada de algunos nichos abiertos en la peńa. Está en un cerro muy escarpado del barranco de Herque, entre Arico y Güímar, en el país de Abona, y tan llena de momias, que no se contaron menos de mil. A la verdad, yo no había admirado tanto hasta entonces aquel artificio con que estos isleños inmortalizaban sus cuerpos, y me sentía penetrado de placer [...]. Las mortajas o forros en que están arrollados desde pies a cabeza son unos pellejos de cabra cosidos con primor. Algunos cuerpos tienen hasta cinco o seis, puestos unos encima de otros. Hállanse los varones con los brazos extendidos sobre ambos muslos y las hembras con las manos juntas hacia el vientre. Aun la misma colocación que tienen los xaxos en este cementerio es objeto digno de atención, porque están en camas y filas, sobre unos como andamios o catrecillos de madera todavía incorrupta, cuyo espectáculo no tiene nada de honroso» ${ }^{41}$.

Con casi total seguridad este hallazgo también es referenciado por Quesada y Chaves ${ }^{42}$, quien menciona tres momias, «en el de 1765 fueron hallados tres cuerpos de Hidalgos en una Cueva de la Parroquia de Arico que uno de ellos fue presentado a la Mag. de Nro. Católico Rey D. ${ }^{\mathrm{n}}$ Carlos III y los otros fueron a varios Reinos", lo que sugiere que no sólo se enviaron a Francia, sino también a Inglaterra.

La referencia al «barranco de Herque, entre Arico y Güímar» por Viera y Clavijo, aunque actualmente se encuentra entre Güímar y Fasnia, se debe a que el municipio de Fasnia quedó integrado en Arico entre 1723 y 1795. Por otro lado, el que la incluya dentro del "país de Abona» y no de Güímar apunta a que apareció en la margen derecha de Fasnia. Su descubrimiento en Arico según Quesada y Chaves vuelve a sugerir que la cueva se encontraba en la margen derecha del municipio de Fasnia. El desconocer quizás este dato ha llevado a Diego Cuscoy ${ }^{43}$ a proponer que

40 Guerra y Peña, L.A. de la, opus cit., n. ${ }^{\circ} 29$, p. 76.

41 Viera y Clavijo, J. DE, opus cit., n. ${ }^{\circ} 23$, pp. 174-175.

42 Quesada y Chaves, D. De (2007 [1784]): Canaria Ilustrada y puente americano. En P. Fernández-Palomeque, C. Gómez-Pablos y R. Padrón (eds.). La Laguna, p. 303.

43 Diego Cuscoy, L. (1968): Los Guanches. Vida y cultura del primitivo habitante de Tenerife. Tenerife, p. 241. 

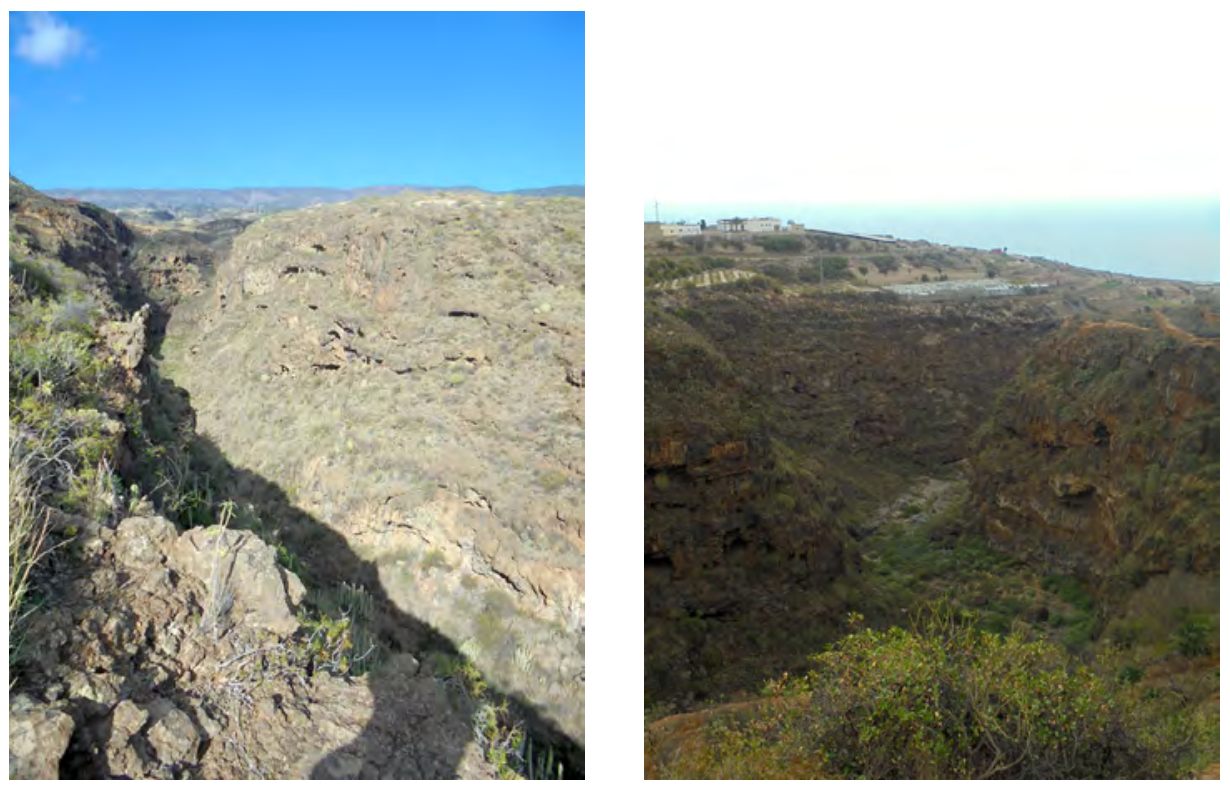

Fig. 4a-4b. Vista de los cauces bajo y medio del barranco de Erques (Güímar-Fasnia).

procederían de una cueva situada en el barranco de Juan Andrés de Arico y no en el barranco de Erques. Por otra parte, otros autores han apuntado que se encontraría en El Escobonal, mencionándose la cueva de las Calzadas ${ }^{44}$ o cueva del Camino Real (Gustavo González, com. pers.), que son las dos denominaciones tradicionales, pero la cueva se encuentra en la margen derecha de Fasnia, no en la izquierda de Güímar, y por tanto pertenecería al menceyato de Abona. Otros investigadores, por cuestiones toponímicas, han propuesto la zona de El Guaco en los altos de Güímar, a $1 \mathrm{~km}$ de El Bailadero de las Lajas y la fuente Copa o de Juan Álvarez, y a algo más, en dirección opuesta, de La Campana, que interpreta como wa-ku «este [lugar] de todos» por tratarse la cueva de una necrópolis colectiva ${ }^{45}$. Este autor lo asocia también con una cueva de $10 \mathrm{~m}$ de ancho y $100 \mathrm{~m}$ de fondo localizada en agosto de 1876 en El Escobonal donde se extrajeron tres momias, una fragmentada ${ }^{46}$ (figs. $\left.4 a-4 b\right)$.

${ }^{44}$ Rodríguez Delgado, O. (1978): «La investigación arqueológica en la zona de Agache». El Día, Santa Cruz de Tenerife, 18 de junio de 1978; Rodríguez Delgado, O. (1994): Guía de la comarca de Agache (Güimar). Güímar, p. 134.

45 Luca López, F.P. De (2011): «En relación a la Cueva de las Mil Momias». El Día/La Prensa, Santa Cruz de Tenerife, 5 de febrero de 2011, pp. 2-3.

46 Álvarez Rixo, J.A. (1990 [1845-79]): Apuntes sobre restos de los guanches encontrados en el siglo actual. En A. Tejera (ed.). Eres (Arqueología), 1 (1), pp. 129-130. 
Fruto de esta visita se extrajeron un mínimo de tres momias en 1764, aunque Anchieta cita cuatro momias, pero varias pudieron recuperarse en 1772. La primera la conservó en la casa Gabriel Román, donde se la enseñó a Anchieta ${ }^{47}$, quien aporta los datos más precisos. La segunda y mejor conservada la envió Luis Román Jovel, capitán de infantería del regimiento provincial de Güímar y regidor de Tenerife, casado con María Consolación de La Hanty y Bignoni, a su primo el regidor Francisco Javier Machado Fiesco, que residía en Madrid como miembro del Consejo de Indias, quien además era cuñado de Gabriel Román, pues estaba casado con su hermana Anastasia.

La tercera momia la transportó a la península Lorenzo Vázquez Mondragón, administrador de los estancos y de las rentas reales del tabaco, que había llegado a Tenerife el 11 de octubre de $1755^{48}$, pero parece desaparecer el rastro de la momia. En Tenerife contrajo matrimonio con Isabel Botello Calderín ${ }^{49}$. Fue responsable de la renta del tabaco entre 1761 y $1764^{50}$, el año del descubrimiento de las momias.

Un segundo grupo salió de Tenerife en 1772. La cuarta y quizás la quinta fueron transportadas a Francia por un navío francés en 1772. La sexta, séptima y octava fueron trasladadas en 1772 en un barco inglés a Londres, una se entregó al Trinity College de Cambridge, otra al British Museum y la tercera pasó a una colección particular.

La cueva siguió siendo frecuentada por viajeros, volviendo a ser mencionada en 1800. «La más famosa es la del barranco de Herque, entre Arico y Güímar, en el país de Abona [...]. El interior de esta cueva es amplio, con algunos nichos en las paredes; la entrada es escarpada y de un difícil acceso" ${ }^{51}$. No obstante, se menciona otra cueva que también se visitaba. "Existe otra a una legua y media o dos de La Laguna, que es la que normalmente se enseña a los viajeros. Está situada en la ladera de una montaña cortada casi a pico, y sólo se puede ascender a ella con muchos esfuerzos y con ayuda de varias escalas ${ }^{52}$. Dado que la legua castellana es de $4 \mathrm{~km} 190 \mathrm{~m}$, implica una distancia de $8,4 \mathrm{~km}$ aproximadamente y difícilmente puede ser la ya entonces conocida del acantilado de Martiánez en el Puerto de la Cruz, pues la distancia real es de $28,1 \mathrm{~km}$.

La cueva volvió a ser visitada en 1833 , añadiendo algún dato interesante sobre su acceso y en particular una nueva confirmación de su ubicación en el «Barranco de Herque. Allí pude visitar una cueva donde había un enterramiento guanche. Se

47 Anchieta y Alarcón, J. de, opus cit., n. ${ }^{0}$ 5, pp. 15-16 GHI-21.

48 Anchieta y Alarcón, J. de, opus cit., n. ${ }^{\circ}$ 24, p. 156.

49 Anchieta y Alarcón, J. de, opus cit., n. ${ }^{\circ} 24$, p. 506.

${ }^{50}$ LuxÁn, S. y Solbes, S. (2000): «El funcionamiento del estanco del tabaco en Canarias y en Navarra (1730-1780): un ejercicio de historia comparada». En F. Morales Padrón (ed.): XIII Coloquio de Historia Canario-Americana (Las Palmas, 1998). Madrid-Las Palmas, pp. 2006, 2020 n. ${ }^{\circ} 10$.

51 Bory de Saint-Vincent, J.B.G.M. (1988 [1803]): Ensayo sobre las Islas Afortunadas y la antigua Atlántida o compendio de la Historia General del Archipiélago Canario. La Orotava-Tenerife, p. 47.

52 Bory de Saint-Vincent, J.B.G.M., opus cit., n. ${ }^{\circ}$ 51, p. 47. 


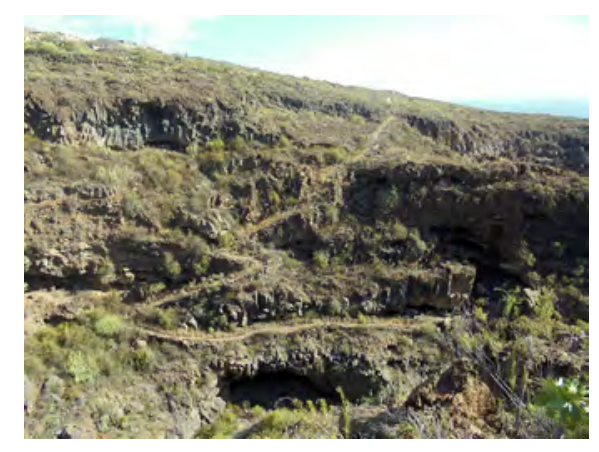

Fig. 5a. Camino real descendente desde El Escobonal hacia el barranco de Erques.

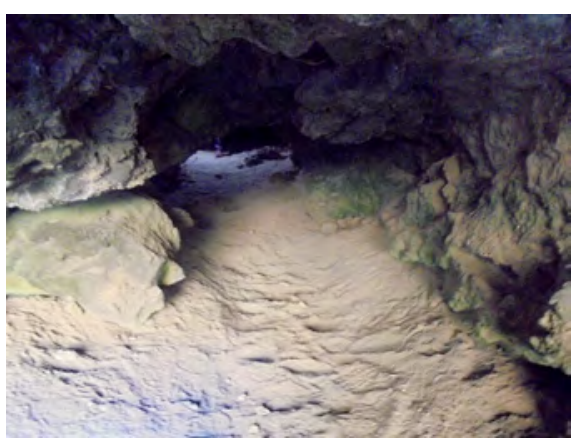

Fig. 5b. Entrada de acceso a la cueva de las Calzadas (Fasnia).

entra por dos aberturas relativamente pequeñas horadadas en la piedra, que conducen a una bóveda natural grande y oscura. Hace tiempo aquí reposaban un número considerable de momiass ${ }^{33}$.

Diversos autores han descartado que se trataría de la cueva de las Calzadas por encontrarse muy cerca de la costa, la ausencia del aire seco de alta montańa que facilitaría su preservación y la insuficiente superficie de la cueva ${ }^{54}$, aunque nunca creemos que hubo ni 300 ni 1000 momias. Sin embargo, varias razones sugieren no descartar este emplazamiento a la espera de una excavación de comprobación. En primer lugar, su emplazamiento junto al camino real, pues sería un sitio relativamente accesible desde Candelaria y Güímar que habría facilitado su hallazgo y visitas ocasionales desde el siglo Xvi. Como segundo punto, la ubicación en la margen derecha de Fasnia, la margen de Arico en el siglo XvinI, como señalan Quesada y Daubenton (vide infra) en fechas casi contemporáneas al hallazgo y la adscripción a Abona que propone Viera y Clavijo. En tercer lugar, las propias dimensiones de este tubo volcánico, más grande de lo que parece cuando se entra, que permiten moverse con comodidad por su interior, aunque actualmente tiene numerosos derrumbes (figs. 5a-5d).

En sus inmediaciones, ascendiendo en la margen derecha por la calzada real al andén superior del barranco, se encuentra el tagoro de Tonete, TNT, un yacimiento con excelente visibilidad hacia la montańa de Fasnia a $210^{\circ}$ al S.SE y la punta del Porís de Abona a $185^{\circ} \mathrm{S}$, que tiene la principal concentración de materiales arqueológicos en su lado sureste, más protegido del viento. El emplazamiento

53 Browne, D.J. (2005 [1834]): Cartas desde las Islas Canarias. J.J. Cruz y M. Hernández González (eds.). Tenerife-La Laguna, p. 101.

${ }_{54}$ Tejera, A., Galloway, D., García Pulido, D. y Delgado, J.F. (2010): La Cueva de las Mil Momias. Tenerife, p. 29; Luca LóPez, F.P. DE, opus cit., n. ${ }^{\circ}$ 45, p. 2. 


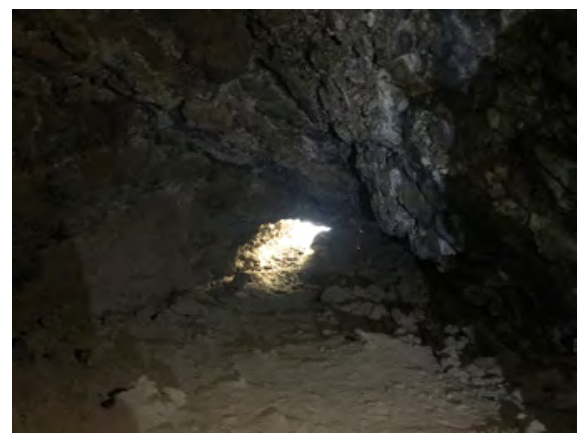

Fig. 5c. Aumento de altura y ancho de la cueva una vez sobrepasada la entrada en la cueva de las Calzadas.

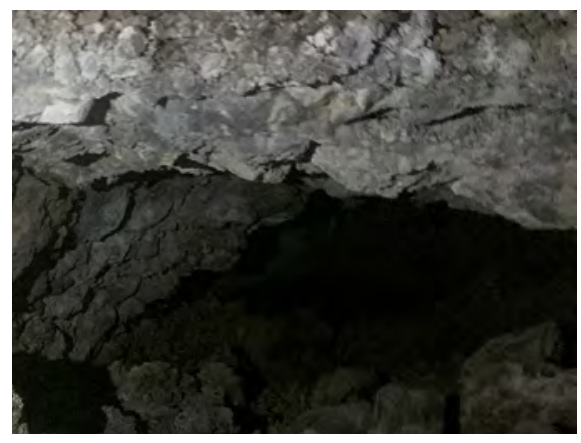

Fig. 5d. Presencia de derrumbes en el interior de la cueva de las Calzadas.

de este tagoro, del que no quedan restos visibles, pues la zona fue puesta en cultivo y fue abancalada y construidos canales de regadío, fue recogido por información oral a fines del siglo XIX con dos denominaciones diferentes por Béthencourt Alfonso ${ }^{55}$, bien como Tagoro de Tónete en Fasnia o bien como Lomo del Tagoro cerca de Erque o Tagoro de Fasnia. Según dicho autor pertenecería al achimenceyato de Fasnia, dentro del menceyato de Abona, fronterizo del menceyato de Güímar ${ }^{56}$.

La cueva del Camino Real o de las Calzadas se encuentra en el tracto inferior y la margen derecha del barranco de Erques. Su acceso se realiza desviándose del sendero por un pequeño camino en dirección NW. La entrada de la cueva se abre en dirección $330^{\circ} \mathrm{N} \mathrm{y} \mathrm{al} \mathrm{inicio} \mathrm{es} \mathrm{un} \mathrm{poco} \mathrm{más} \mathrm{ancha,} 1,40 \mathrm{~m}$ de altura por 2,55 m de ancho, con restos de un muro de cierre que sólo conserva una hilada de piedras, pero al avanzar por su interior se va cerrando hasta tener $0,80 \mathrm{~m}$ de altura y $0,95 \mathrm{~m}$ de ancho, y poco después se abre un tubo volcánico bastante amplio que no presenta una superficie horizontal, sino se asciende primero para luego descender. En superficie, a primera vista, no se observan restos humanos en su interior.

\section{EL TRASLADO DE LA MOMIA MASCULINA DE MADRID A LA SALA DE ANTIGÜEDADES DE LA REAL BIBLIOTECA (1766)}

El proyecto de una Real Librería fue culminado por Felipe $\mathrm{V}$ en diciembre de 1711 a sugerencia de su confesor, el jesuita Pierre Robinet, conformando un Museo de la Real Biblioteca. El grueso de la colección lo constituyó un monetario

55 Béthencourt Alfonso, J. (1994 [1912]): Historia del Pueblo Guanche. II. Etnografía y Organización socio-politica. M.A. Fariña (ed.). La Laguna, p. 116 n. ${ }^{\circ} 7$.

56 Béthencourt Alfonso, J., opus cit., n. ${ }^{\circ}$ 55, p. 87. 
que pasó a denominarse Museo de Medallas ${ }^{57}$, pero dentro también se incluyeron antigüedades egipcias, grecorromanas, piezas etnográficas y de arte procedentes de la colecciones privadas de los reyes desde Carlos I, las cuales se acabaron ubicando en un pasadizo que unía el Palacio Real con el convento de La Encarnación ${ }^{58}$.

La clave de la llegada de la momia a la Real Biblioteca de Madrid, actualmente en el Museo Arqueológico Nacional, lo aporta una nota de Sanz y Chanas, revalorizada por Manuel de $\mathrm{Paz}^{59}$, donde se dan los datos más precisos. «En el Gabinete de historia natural de S.M. Católica se conserva la más perfecta de estas momias llamadas guanches, que en julio de 1764 envió de la isla de Tenerife el capitán de infantería D. Luis Ramón Jobel [Román Jovel], natural de dicha isla, a su primo D. Francisco Javier Machado Fiesco, actual ministro de capa y espada del Real y Supremo Consejo de Indias, con el fin de que la presentase al Rey nuestro señor. Llegó dicho cadáver a la Aduana de Madrid el 23 de Agosto de [17]64, y se mantuvo en casa del expresado ministro hasta el día 16 de diciembre de 1766, en cuyo día a las diez y media de la mañana le hizo pasar a la Real Biblioteca don Bernardo Iriarte, también actual ministro de capa y espada del Consejo de Indias, a quien D. Francisco Javier Machado, que había pasado a Nueva España, dejó esta comisión; y esta entrega en la Real Biblioteca consta por carta del bibliotecario mayor D. Juan de Santander, con fecha de 16 de diciembre de $1766{ }^{60}$.

Como señalaba el Dodsley's Annual Register viI (p. 95), de 10 de agosto de 1764, pocos días antes había llegado a Cádiz «dentro de una larga piel que recuerda a la de un oso [...] un hombre muy joven [...] el cuerpo es enviado a Madrid para ser depositado en la Real Academia de Cirujanos». Junto al cuerpo se enviaron «dos o tres vasos y medio molino de mano, los cuales fueron encontrados en la misma cueva ${ }^{61}$. La descripción sugiere que la momia estaba completamente recubierta por varias capas de pieles que actualmente no conserva, aunque seguramente ya se envió abierta en la zona de la cara que permitió su identificación. Esta envoltura de pie-

57 Alfaro, C., Marcos, C. y Otero, P. (1999): «El Gabinete Numismático: 1711-1999». Tesoros del Gabinete Numismático: las 100 mejores piezas del monetario del Museo Arqueológico Nacional. Madrid.

${ }^{58}$ Fundación y Estatutos de la Librería Pública de El Rey NS Don Phelipe (1716). Madrid; Mañueco Santurtún, C. (1993): «Antecedentes del Museo Arqueológico Nacional (17111867)». Boletín de la ANABAD, 43 (3-4), pp. 12-14; Mañueco Santurtún, C. (2004): «El Gabinete de Antigüedades y el Museo de Monedas de la Real Librería (1711-1759)». En E.M. ${ }^{a}$ Santiago (ed.): La Real Biblioteca Pública, 1711-1760: de Felipe Va Fernando VI. Madrid, pp. 301-316.

59 Paz Sánchez, M. de (2016): «Edición, introducción y notas». J. de Viera y Clavijo, Historia de Canaria. I. Tenerife, pp. 449-450 n. ${ }^{\circ} 10$.

${ }^{60}$ Sanz y Chanas, G.M. (1788): Encyclopedia metódica. I. Historia Natural de los Animales. Madrid, pp. 81-82 nota.

${ }^{61}$ Pettigrew, T.J. (1834): A history of Egyptian mummies, and an account of the worship and embalming of the sacred animals by the Egyptians; with remarks on the funeral ceremonies of different nations, and observations on the mummies of the Canary islands, of the Ancient Peruvians, Burman priests, etc. London, pp. 234-235. 
les creemos que debería haber sido originariamente completa, como han sugerido Álvarez Sosa y Morfini ${ }^{62}$.

Como puede observarse, la momia no fue entregada directamente al rey, sino que Francisco Javier Machado Fiesco y Yáńez, nacido en La Laguna el 11 de diciembre de 1730, regidor perpetuo de Tenerife por renuncia de su padre en 1749, diputado general por las Islas Canarias desde 1757, autor del Mapa General de las Islas Canarias en 1762, fue elegido en febrero de 1765 como secretario de la visita general de Nueva España, para acompañar al visitador general José de Gálvez. Por ello embarcó el 26 de abril, estancia que se prolongó hasta 1772, cuando regresó a España $^{63}$. Quizás por su cargo de diputado general por las Islas Canarias tenía la momia para enseñarla a personas que trataba en Madrid, como señala Anchieta ${ }^{64}$, «en la Corte, para que se vea cómo hay cuerpos conservados al cabo de tantos años». Al prolongarse la estancia en América probablemente decidió ceder la momia a la colección de la Real Biblioteca, seguramente presentada como regalo al rey, como indica Quesada y Chaves ${ }^{65}$, «en [...] 1765 fueron hallados tres cuerpos de Hidalgos en una Cueva de la Parroquia de Arico que uno de ellos fue presentado a[l] [...] Rey D. ${ }^{n}$ Carlos III». Se encargó de la entrega Bernardo Iriarte Nieves Ravelo, nacido en el Puerto de la Cruz en 1735, sobrino de Juan de Iriarte, bibliotecario del rey, que por entonces ocupaba el puesto de oficial mayor de la secretaría de Estado (fig. 6).

\section{LA CREACIÓN DEL REAL GABINETE DE HISTORIA NATURAL Y SU SALA DE ANTIGÜEDADES (1776)}

El 17 de octubre de 1771, Carlos III aceptó el donativo de las colecciones que había reunido Pedro Franco Dávila en París, donde había residido desde 1745, y que parcialmente había vendido entre diciembre de 1767 y enero de 1768 en París por 800000 reales $^{66}$. La donación iba destinada a la creación de un Real Gabinete de Historia Natural, recibiendo a cambio su futura dirección y un sueldo vitalicio de 60000 reales de vellón anuales. El Real Gabinete no se abrió al público hasta el 4 de noviembre de 1776 en el segundo piso del Palacio de Goyeneche de la calle de Alcalá 13, que había sido propiedad del conde de Saceda, comprado en mayo de 1773, donde también se preparó una Sala de Antigüedades, mientras la Real Academia de Bellas Artes de San Fernando se instaló en el primer piso. Se solicita-

62 Álvarez Sosa, M. y Morfini, I. (2014): Tierras de Momias. La técnica de eternizar en Egipto y Canarias. Tenerife, p. 104 fig. 35.

63 Guimerá Peraza, M. (1997): «El ilustrado hacendista Francisco Javier Machado Fiesco (1730-1808)». Anuario de Estudios Atlánticos, 43, pp. 213, 215-216, 264, 273.

${ }^{64}$ Anchieta y Alarcón, J. de, opus cit., n. ${ }^{\circ} 5$, p. 15 GHI-21.

${ }^{65}$ Quesada y Chaves, D. De, opus cit., n. ${ }^{\circ}$ 42, p. 303.

${ }^{6}$ Dávila Ruiz De Eguino, P.F. (1767): Catalogue Systématique et Raisonné des Curiosités de la Nature et de l'Art qui composent le Cabinet de Monsieur Davila. Jean-Baptista-Louis de Rome de Lisle (ed.). I-III. Paris. 


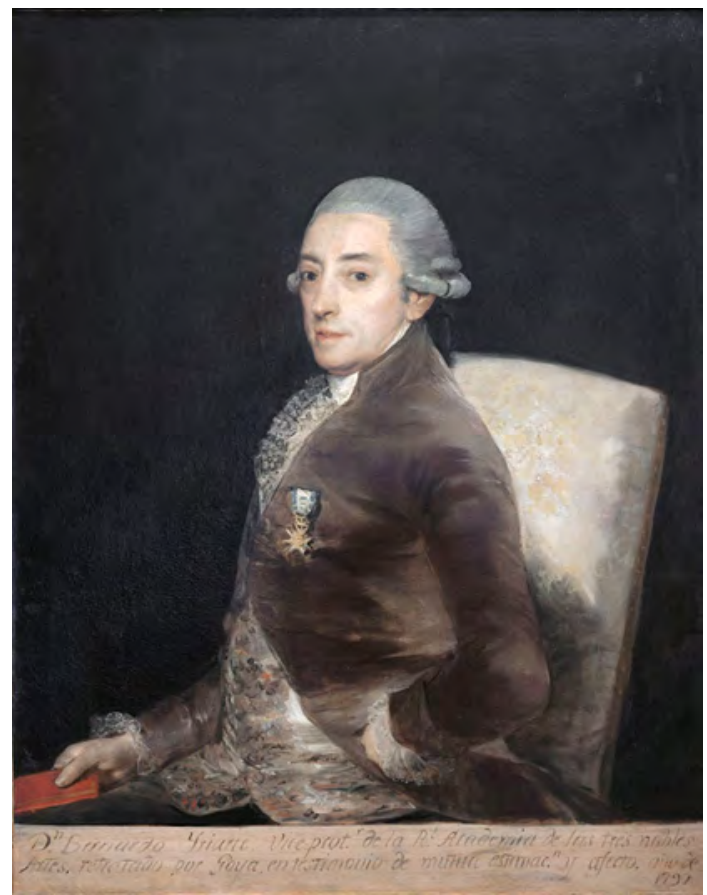

Fig. 6. Retrato de Bernardo de Iriarte por Francisco de Goya (1797). Museo de Estrasburgo.

ron nuevas adquisiciones a los cargos administrativos del reino como gobernadores, virreyes, etc., a raíz de su apertura ese mismo año de 1776 por medio de una Instrucción para que se recogiesen objetos de historia natural. Dávila dirigió el Gabinete hasta su muerte en enero de $1786^{67}$, con la creciente colaboración del lanzaroteño José Clavijo y Fajardo ${ }^{68}$, quien realizó el inventario del Gabinete, dentro de su labor como formador de índices y secretario para la correspondencia de dentro y fuera del Reino. Al morir Dávila en 1786, Clavijo pasó a ocupar la subdirección del Real Gabinete (figs. 7a-7b).

El traslado de la momia de la Real Biblioteca a la del Real Gabinete de Historia Natural se produjo un mes antes de la apertura, como se indica en un texto casi contemporáneo. «En 28 de septiembre de 1776 se pasó real orden [...] por el excelentísimo señor marqués de Grimaldi [Pablo Jerónimo Grimaldi, Secretario de

67 Calatayud Arinero, M. ${ }^{a}$ A. (1988): Pedro Franco Dávila y el Real Gabinete de Historia Natural. Madrid.

68 Espinosa, A. (1970): Don José Clavijo y Fajardo. Las Palmas de Gran Canaria. 


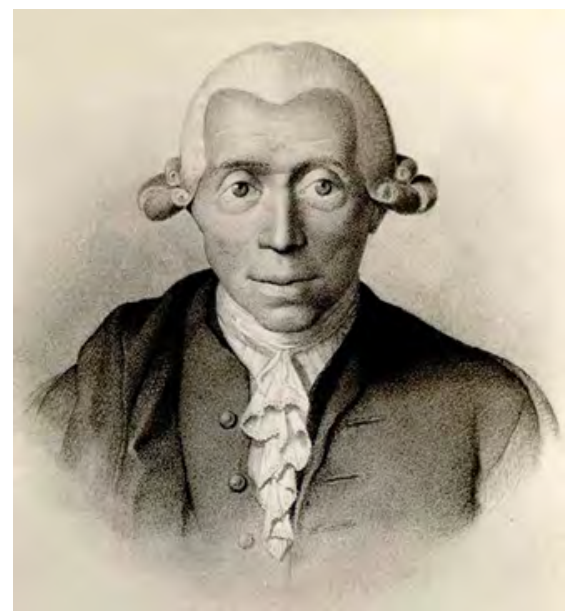

Fig. 7a. Retrato de Pedro Franco Dávila. Museo Nacional de Ciencias Naturales.

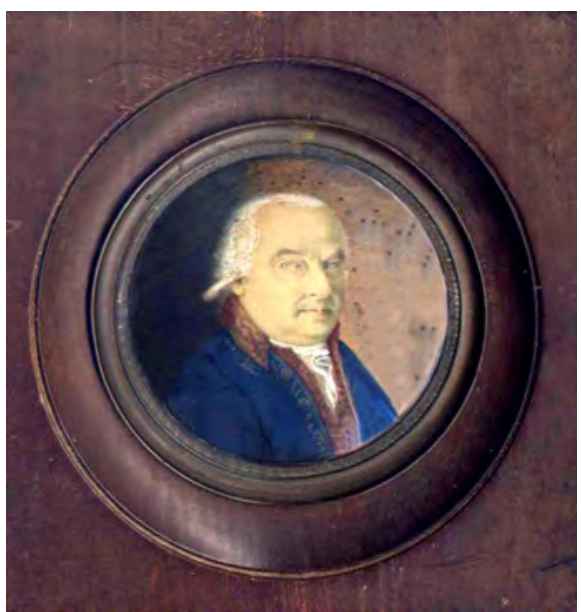

Fig. 7b. Retrato de José Clavijo y Fajardo. Ayuntamiento de Teguise.

Estado y del Despacho del Consejo de Estado] para que entregase al director del Real Gabinete, D. Pedro Franco Dávila, con lo demás que hubiese perteneciente a Historia Natural en la Biblioteca Real, a fin de colocarlo todo en el Real Gabinete; y, en fecha de 2 de octubre escribió D. Juan de Santander al enunciado director para que el día siguiente enviase por el cadáver, que en efecto se trajo y colocó el día $3 »^{69}$.

Los datos muy precisos de Sanz muestran que pudo consultar la documentación en el propio Real Gabinete. Eso lo confirman dos cartas actualmente en el Museo Nacional de Antropología. Por carta del 2 de octubre de 1776 de Pedro Franco Dávila a Juan de Santander, bibliotecario Mayor. «Muy S[eñor]. mío que mañana me entregará de orden de (Su Majestad) el cadáver del Guanche para que lo coloque en este R.[eal] Gabinete [de Historia Natural] de mi cargo. En mi supuesto enviaré à las 10 de la mañana à (nuestro) conserge (Don Juan) Berton, para que lo reciva». Una segunda misiva de 7 de octubre de 1776 de Pedro Franco Dávila al marqués de Grimaldi: «el (Señor Don Juan) de Santander me entregó el día 3 de este el cadaver disecado del Guanche q[ue] tenía en la [Real] Biblioteca el que queda a mi cuydado en este R. [eal] Gabinete» ${ }^{70}$.

La momia permaneció en el Real Gabinete de Historia Natural hasta que fue trasladada a la antigua sede del Museo de Anatomía del doctor Pedro Gonzá-

69 Sanz y Chanas, G.M., opus cit., n. ${ }^{\circ}$ 60, pp. 81-82 nota.

70 Mora Postigo, C. (1995): «Momias guanches en el Museo Nacional de Etnología». I Congreso Internacional de Estudios sobre Momias (Puerto de la Cruz, 1992). I. La Laguna, pp. 267-268. 
lez de Velasco. Este museo fue fundado en 1875 , pero al fallecer su propietario en 1882, el edificio fue comprado a la familia en 1888 , mientras las colecciones antropológicas fueron donadas al Estado ${ }^{71}$. Quedó adscrito a la sección de Antropología, Etnografía y Prehistoria del Museo Nacional de Ciencias Naturales bajo la dirección de la sección por Manuel Antón, a cuyo edificio fue trasladada la momia en 1895. En esta nueva sede fue visitada en 1908 por Béthencourt Alfonso ${ }^{72}$ : «Momia guanche. Tendido; manos por bajo de la parte externa de los ilíacos, con las manos tendidas sobre la parte anterior externa de los muslos. Dedos gordos de los pies unidos por una correa. Parece momificado por desecación. Color de la piel amarillento. La cabeza como tumbada sobre el hombro derecho. Brazos tendidos y unidos al cuerpo siguiendo las formas de éste. Tobillos unidos (el derecho más arriba que el izquierdo); rodillas unidas, pero la izquierda más arriba que la derecha; pene al parecer muy grande».

En mayo de 1910 se creó el Museo Nacional de Antropología, Etnología y Prehistoria escindiéndolo del Museo Nacional de Ciencias Naturales, que siguió bajo la dirección de Manuel Antón, donde se le asignó el número de inventario 3332. En septiembre de 1930 el museo quedó bajo la supervisión del Instituto Nacional de Ciencias, dependiente de la Junta de Ampliación de Estudios, desarrollándose un Reglamento ${ }^{73}$ que articuló el funcionamiento del Museo Nacional de Ciencias Naturales, el Museo Antropológico y el Jardín Botánico. El Museo Antropológico cambió su nombre por el de Museo Nacional de Etnología en 1939, aunque permaneció cerrado después de la Guerra Civil hasta junio de 1945, bajo la dirección de José Pérez de Barradas, nombrado director en noviembre de $1939^{74}$. Conservó esta denominación hasta 1993, cuando recuperó su nombre originario. Allí permaneció la momia hasta que fue trasladada al Museo Arqueológico Nacional, donde quedó expuesta desde el 14 de diciembre de 2015 en la nueva sección canaria ${ }^{75}$.

La momia corresponde a un hombre de 35 a 40 ańos, de 1,62 $\mathrm{m}_{\text {de altura }}{ }^{76}$, aunque previamente se había indicado $1,60 \mathrm{~m}$ y 35-45 años ${ }^{77}$, que le han retirado las

71 SÁnchez Gómez, L.A. (2014): «El Museo Antropológico del doctor Velasco (anatomía de una obsesión)». Anales del Museo Nacional de Antropología, 16, p. 285.

72 Béthencourt Alfonso, J., opus cit., n. ${ }^{\circ}$ 55, p. 606.

${ }_{73}$ Reglamento de los Museos, Nacional de Ciencias Naturales, Antropológico y Jardín Botánico (1930): Madrid.

74 SÁnchez Gómez, L.A. (2008): «Antropologías para después de una guerra. Plenitud y declive de la obra antropológica de José Pérez de Barradas (1939-1952)». En E. de Carrera y A. Martín Flores (eds.): Arqueología. América. Antropología. José Pérez de Barradas 1897-1981. Madrid, pp. 399, 413.

${ }^{75}$ Maicas, R. y Mederos, A. (2016): "Arqueología canaria en el Museo Arqueológico Nacional». Boletín del Museo Arqueológico Nacional, 34, pp. 446-448 fig. 4-6.

76 Gómez Espinosa, T., Carrascoso, J. y Badillo, S. (2018): «La momia guanche del Museo Arqueológico Nacional. De las fuentes históricas a la tomografía computerizada». Boletín del Museo Arqueológico Nacional, 37, pp. 457, 462.

77 Llagostera Cuenca, E. (1993): «Estudio antropológico de la momia guanche MadridI». Boletín de la Asociación Española de Orientalistas, 29, pp. 38, 40. 

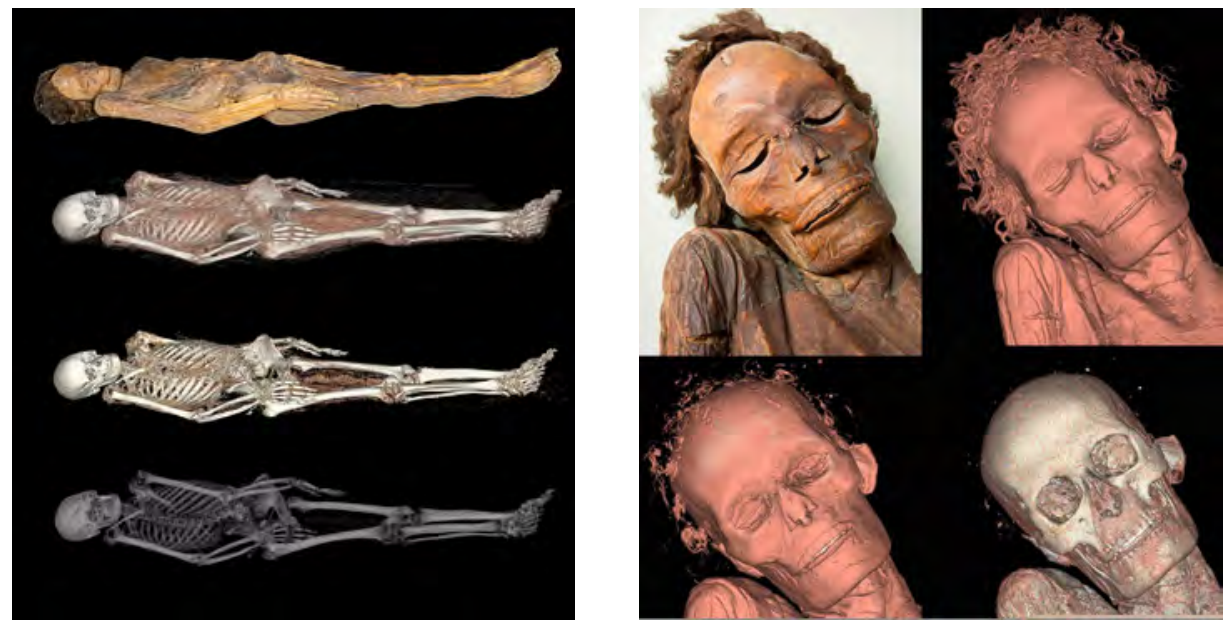

Figs. 8a-8b. TAC de la momia masculina del barranco de Erques

(Fasnia, Tenerife) (1764). Museo Arqueológico Nacional.

pieles que lo recubrían. El TAC muestra que el cerebro no ha sido extraído. Tampoco lo han sido los órganos internos, corazón, pulmones, hígado, riñones, vesícula y estómago, por lo que no hay indicios de eviscerado ${ }^{78}$. El elemento más llamativo es la identificación de un relleno inorgánico en la zona del recto que se considera que se ha introducido por la putrefacción del colon y no por la extracción previa del intestino y el colon ${ }^{79}$. Algunos autores consideran que la momia tiene una peluca de color castaño y el cabello pegado ${ }^{80}$, mientras otros creen que no es una peluca, sino mechones sueltos pegados ${ }^{81}$. Las manos tienen las uñas bien recortadas y muy bien cuidadas, que no se corresponden a una persona que realizase trabajos pesados, mientras los dedos gordos o primeros de los pies se unen a los otros dedos por una ligadura de tripa o piel ${ }^{82}$. Parece que cojeaba porque la pierna derecha es algo más corta que la izquierda ${ }^{83}$ (figs. 8a-8d).

La momia fue datada en 1990 por una muestra de piel remitida por C. Mora del Museo Nacional de Etnología al laboratorio de Oxford en 1989, OxA-

${ }^{78}$ Gómez Espinosa, T., Carrascoso, J. y Badillo, S., opus cit., n. ${ }^{\circ}$ 76, pp. 457, 459 fig. 6 , 460, fig. 7 .

79 Gómez Espinosa, T., Carrascoso, J. y Badillo, S., opus cit., n. ${ }^{\circ}$ 76, p. 461 fig. 8.

${ }^{80}$ Gómez Espinosa, T., Carrascoso, J. y Badillo, S., opus cit., n. ${ }^{\circ}$ 76, p. 462.

${ }^{81}$ Llagostera Cuenca, E., opus cit., n. ${ }^{\circ} 77$, pp. 38-39.

82 Llagostera Cuenca, E., opus cit., n. ${ }^{\circ} 77$, p. 40.

${ }^{83}$ Llagostera Cuenca, E., opus cit., n. ${ }^{\circ} 77$, p. 39. 
$2231800 \pm 60 \mathrm{BP}^{84}, 1058$ (1256) 1296 a.C. Sin hacer referencia a este análisis se ha vuelto a datar "por primera vez» la momia con otras dos muestras de piel del hom-

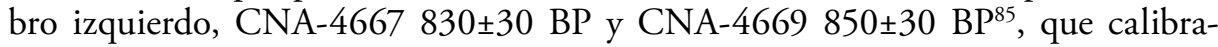
das también señalan una fecha de la primera mitad del siglo XıII d.C., 1161 (1218) 1276/1262 AC y 1154 (1212) 1261 AC.

\section{LA SEGUNDA MOMIA FEMENINA DEL REAL GABINETE DE HISTORIA NATURAL (1778)}

El ingreso de la momia masculina en el Real Gabinete propició que su director Dávila, quizás a instancias del lanzaroteńo José Clavijo y Fajardo, cuyo padre, Nicolás Clavijo, era originario de La Orotava (Tenerife), tratase de tener también una segunda momia femenina en la colección. Para ello contactó con Luis Arguedas y Brugieros, de la Real Compañía de Guardiamarinas, que había participado en la expedición de caballero Borda en 1776 junto con el profesor de la Escuela de Guardiamarinas de Cádiz, José Varela y Ulloa. Para la gestión del transporte entre Tenerife y Cádiz colaboró Vicente Tofiño de San Miguel y Wanderiales, director de la Escuela de Guardiamarinas de Cádiz y del Real Instituto y Observatorio de la Armada con sede en San Fernando (Cádiz). Por carta enviada el 26 de mayo de 1778 desde Cádiz por Vicente Tofiño al director Pedro Franco Dávila, «Juaquin Román entregará a V[uestra]m[erce]d. la Momia que halló en Tenerife d[o]n. Luis Arquedas, cuyo porte ajusté en Cadiz en veinte pesos sencillos, que aunque excede al peso del cajon fue preciso combenir, porque la aprehension de ser un Cadaver hizo que se negasen otros conductores. Lleva despacho para que no se registre, ni abra dicho cajon, y me parece que bá estivado en terminos que no padezca más de lo que padecio en el viaje por mar en donde la humedad y calor de la bodega del navio alteró mucho su conservacion, segun me dijo el mismo Arquedas» ${ }^{86}$.

En la respuesta de 16 de junio de 1778 de Pedro Franco Dávila a Vicente Tofiño le indicaba: «No he respondido antes a su muy estimada de Vd. de 26 del pasado hasta poderle avisar el resivo de la Momia que en efecto me entregó el Arriero Joaquín Roman con quien Vd. se sirvió emviarmela, y en consecuencia del ajuste que Vd. hizo con el mencionado por su transporte le entregué los trescientos reales de Vellon, há llegado algo maltratada teniendo la caveza separada del Cuerpo, y un poco humeda toda ella, lo que podrá muy bien ser de la navegación de Cana-

${ }^{84}$ Hedges, R.E.M., Housley, R.A., Bronk, C.R. y van Klinken, G.J. (1992): «Radiocarbon dates from the Oxford AMS system: Archaeometry datelist 14». Archaeometry, 34 (1), p. 150.

85 Sánchez Cabrero, B. y Gómez Espinosa, T. (2018): «Datación mediante carbono 14 de la momia guanche del Museo Arqueológico Nacional». Boletín del Museo Arqueológico Nacional, 37, p. 175.

${ }^{86}$ Calatayud Arinero, M. ${ }^{2}$ A. (1987): Catálogo de documentos del Real Gabinete de Historia Natural (1752-1786). Fondos del Archivo del Museo Nacional de Ciencias Naturales. Madrid, p. 182 n. ${ }^{\circ}$ 506; Mora Postigo, C., opus cit., n. ${ }^{\circ} 70$, p. 268. 


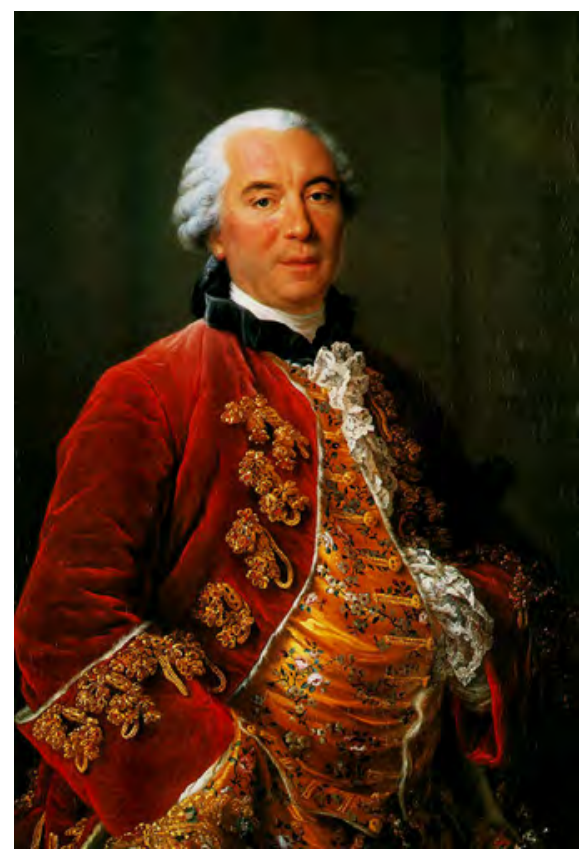

Fig. 9. Retrato de Jean Louis Leclerc, conde de Buffon, por Francois Hubert Drouais (1761). Museo Buffon, Montbard.

rias. Aqui tenemos del mismo parage de Canarias un Cadaver de hombre muerto mejor conservado y este solo lo deseaba por(que) me havian (dicho) hera del Sexo contrario ${ }^{87}$. Por probable confusión se ha indicado que esta momia llegó en $1777^{88}$.

\section{LAS DOS MOMIAS CANARIAS DEL MUSÉE NATIONAL D'HISTOIRE NATURELLE DE PARIS (1772-76)}

A las colecciones reales francesas del Jardin des Plantes Médicinales, fundado en 1635 por Luis XIII, entonces bajo la dirección de Georges Louis Leclerc, conde de Buffon, se incorporaron dos momias procedentes de Tenerife, quizás una en 1772 y otra en 1776, posteriormente posiblemente trasladadas al Musée de l'Homme y sean una de las seis momias canarias existentes en dicho museo (fig. 9).

${ }^{87}$ Mora Postigo, C., opus cit., n. ${ }^{\circ} 70$, p. 268.

${ }^{88}$ Gómez Espinosa, T., Carrascoso, J. y Badillo, S., opus cit., n. ${ }^{\circ}$ 76, p. 456. 
Los datos de las dos últimas momias son recogidos por Louis Jean-Marie Daubenton unos 15 años después. «En el Gabinete de Historia Natural del Jardín del Rey en París se ven dos de estas momias, que trajo de la isla de Tenerife en 1776 el conde de Chastenet Puységur [Antoine Hyacinthe Anne de Chastenet], alférez de navío, que mandaba entonces la embarcación llamada l'Espiègle; se encontraron en una caverna del lugar de Arico; están envueltas en pieles y la una tiene descubierta la cabeza, la piel está seca y las facciones del rostro no bien descubiertas, pero los cabellos están unidos a la piel y bien conservados; le faltan los pies, pero se le ven las extremidades de los huesos de las piernas ${ }^{89}$. De esta fuente la debió copiar Viera y Clavijo en su ejemplar ya editado y fue recogido como una nota por Cioranescu en la edición del texto ${ }^{90}$. Como puede observarse llegaron a París dos momias y no una como indica Anchieta ${ }^{11}$, pero por los años transcurridos no cabe descartar que fueran extraídas de la misma cueva años después.

La referencia a Arico que recoge Daubenton coincide con la mención de Quesada y Chaves y reafirma la ubicación de la cueva en la margen derecha del barranco de Erques, dentro del municipio de Fasnia, límite oriental del menceyato de Abona.

El conde de Chastenet Puységur había sido subordinado en la embarcación de La Flore que dirigía Verdun de la Crenne en la expedición de 1771 y $1772^{92}$. En un segundo viaje que llegó a Tenerife el 20 de julio de 1776, ya con el conde como comandante de la corveta L'Espiègle, a las órdenes del caballero Jean Charles Borda que comandaba el navío La Boussole, solicitó al rey de España poder adquirir alguna momia para el Museo de Historia Natural de París. Por esta razón el traslado de al menos una momia le es atribuido a Borda por Berthelot, de la cual indica además su sexo, «mujer guanche momificada, traída por el caballero Borda y depositada en las galerías de Anatomía del Museo de Historia Natural de París»" ${ }^{93}$. Sin embargo, en un texto posterior, con una breve biografía del conde de Chastenet Puységur ${ }^{94}$, se considera que la solicitud y consecución de las momias se había producido durante la visita de 1772 .

La presencia de estas dos momias en París la recogía Viera y Clavijo ${ }^{95}$ : «El gabinete real de Madrid posee una muy preciosa, otra el de Londres, otra el de Utrecht, dos el de París, etc.».

${ }^{89}$ Daubenton, L.J.M. (1782): Encyclopédie Méthodique: Histoire Naturelle des Animaux. I. Paris, p. 86; Sanz y Chanas, G.M., opus cit., n. ${ }^{\circ}$ 60, pp. 81-82.

${ }_{90}$ Viera y Clavijo, J. De, opus cit., n. ${ }^{\circ} 23$, p. 175 n. ${ }^{\circ} 1$.

${ }^{91}$ Anchieta y Alarcón, J. de, opus cit., n. ${ }^{\circ}$ 5, p. 15 GHI-21.

92 Verdun de la Crenne, J.R.A., Borda, J.Ch. y Pingré, A.G. (1778): Voyage fait par ordre du roi en 1771 et 1772, en diverses parties de l'Europe, de l'Afrique et de l'Amérique. I-II. Paris.

${ }^{3}$ Berthelot, S. (1978 [1840-42]): Etnografía y Anales de la Conquista de las Islas Canarias. Tenerife, p. 167.

94 Feller, F.X. De y Pérennes, M. (1833-34): Biographie universelle ou Dictionnaire historique contenant la nécrologie des hommes célèbres. X. Paris, pp. 333-334.

${ }^{95}$ Viera y Clavijo, J. De (1982 [1799-1810]): Diccionario de Historia Natural de las Islas Canarias. Indice alfabético descriptivo de sus tres reinos: animal, vegetal y mineral. M. Alvar (ed.). Madrid, p. 291. 


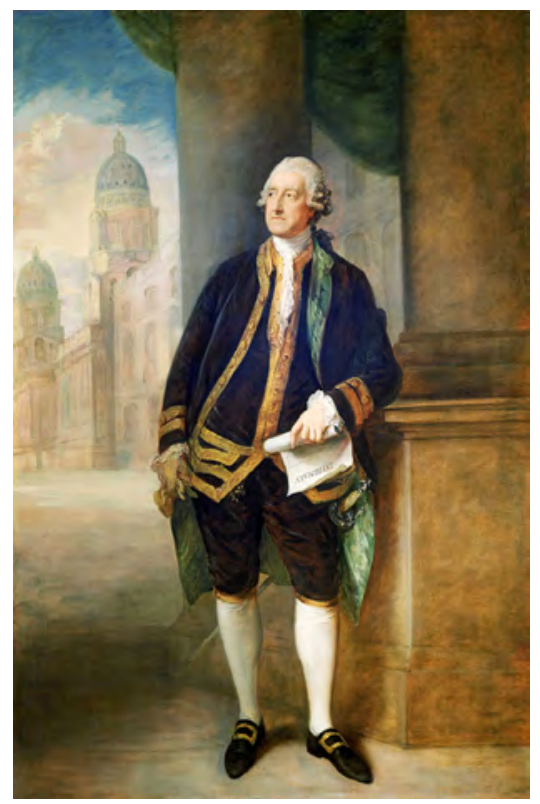

Fig. 10. John Montagu, IV conde de Sandwich, por Thomas Gainsborough (1782). National Maritime Museum. The Royal Collection Trust. Londres.

\section{LA MOMIA DEL TRINITY COLLEGE DE CAMBRIDGE (1772)}

Una sexta momia llegó a Londres en octubre de 1772. «Aquí se asegura que se vá á colocar en el Museo Británico una momia que traxeron á esta ciudad en el mes de octubre del año [...] pasado. Esta momia en que se perciben distintamente los nervios, tendones, venas y arterias, se encontró con otras muchas en una cueba del pico de Tenerifes ${ }^{96}$.

Por la información que nos proporciona Lettsom ${ }^{97}$ la momia de Cambridge había sido donada por John Montagu, lord Sandwich, chancellor de la Universidad de Cambridge, que había estudiado en el Trinity College, aunque menciona la fecha de 1768, pero sabemos que llegó en 1772 (fig. 10).

Esta referencia es recogida por Viera y Clavijo: «En octubre de 1772, el señor Young, comandante de un bergantín inglés, sacó de Tenerife la momia de una guanche, que colocó en el Museo Británico. Con este motivo se habló de ella en los papeles públicos como de una gran maravilla. Celebrose la frescura y buena

96 Mercurio Histórico y Politico, marzo (1773), pp. 246-247.

${ }^{97}$ LetTsom, J.C. (1778): History of the Origin of Medicine. London, p. 81. 
conservación de las partes del cuerpo, aun las más menudas [...]. Pero fue un error asegurar que se encontró con otros en una cueva de la cima del Pico. En este paraje no hay tales sepulcros. Díjose también que le compró; pero en Tenerife no se hace tráfico de estos cuerpos, y sólo daría alguna gratificación a los paisanos que acaso entrarían con sobrado riesgo en la caverna sepulcral $»^{98}$. Sin embargo, la ubicación de la momia en Londres no es correcta y estuvo depositada en la Biblioteca del Trinity College en Cambridge hasta que fue trasladada en 1914 al University Museum of Archaeology and Ethnology, con el número de inventario D 1914.96.

La llegada de esta momia fue recogida en las fuentes escritas contemporáneas. «Una momia extraordinaria fue traída de Tenerife por el comandante de la fragata Weesel, capitán Young, en octubre pasado, y ha sido depositada en la biblioteca perteneciente al Trinity College, Cambridge [...] El capitán Young habiendo tocado a Tenerife en su viaje de retorno desde la costa de Guinea, tenía la curiosidad de escalar el Pico [del Teide] con un guía; luego, en una cueva (el lugar de enterramiento de los antiguos habitantes paganos), él descubrió varios cadáveres, envueltos en pieles de cabras, uno de los cuales abrió y descubrió un cuerpo perfecto, fresco y no mutilado; algunos tenían siete pies de largo y otros cinco pies y tres pulgadas. El expresó su enorme deseo de obtener uno de estos cadáveres, pero el sacerdote católico puso muchas objeciones. Éstas, sin embargo, se resolvieron con un poco de oro, adquiriendo una momia hembra. El cuerpo es perfecto en todo detalle, y la piel aparece de un color muy bronceado. El pelo es largo y negro y se mantiene rizado; los dientes y las uńas de los pies y manos son frescas" "9 .

En 1837 se destacaba la cuidadosa envoltura de los pies y manos. «En una momia guanche conservada en el museo de Cambridge, se observan los dedos de los pies y de las manos envueltos por separado con tiras de cuero, detalle observado igualmente en las momias de la clase alta de la sociedad egipcia $»^{100}$.

La del Trinity College es una momia masculina, que no supera los 45 años $^{101}$. Se consideró inicialmente femenina por el pelo rizado oscuro que tenía, estar tapando las manos la región pélvica y tener el pene roto ${ }^{102}$. Los dedos de los pies y de las manos estaban protegidos por tiras de piel para retener las uñas ${ }^{103}$. La momia presenta ocho incisiones en la espalda destinadas a introducir elementos inorgánicos para dar una mejor apariencia al cuerpo, los cuales se considera que se distri-

98 Viera y Clavijo, J. de, opus cit., n. ${ }^{\circ} 23$, p. 679.

99 Dodsley's Annual Register, Xvi (1773), p. 66; Pettigrew, T.J., opus cit., n. ${ }^{\circ}$ 61, p. 235; Dawson, W.R. (1927): «Contributions to the History of Mummification». Proceedings of the Royal Society of Medicine, 20, p. 838.

${ }^{100}$ Wilde, W.R. (2000 [1840]): Viaje a Tenerife. M. Tejedor y C. Jahrbeck (eds.). Tenerife-Madrid, p. 67.

101 Brothwell, D.R., Sandison, A.T. y Gray, P.H.K. (1969): «Human Biological Observations on a Guanche Mummy with Anthracosis». American Journal of Physical Anthropology, 30 (3), p. 343 .

102 Dawson, W.R., opus cit., n. ${ }^{\circ} 99$, p. 838, 833 fig. 1-2.

103 Pettigrew, T.J., opus cit., n. ${ }^{\circ}$ 61, p. 234; Dawson, W.R., opus cit., n. ${ }^{\circ}$ 93, p. 840. 
buían alrededor de las incisiones mediante masaje de esa zona ${ }^{104}$. El cabello estaba también pegado pero se propone que el cabello debía ser afeitado antes o durante el proceso de embalsamamiento ${ }^{105}$. En cambio el análisis de rayos $\mathrm{X}$ no dio pistas sobre la posible evisceración de órganos.

En el trabajo de Dawson se enfatizan tres puntos de conexión con la momificación egipcia. En primer lugar, la realización de incisiones en el cuerpo para introducir elementos inorgánicos para dar mejor apariencia al cuerpo que se generaliza en Egipto al comenzar el Tercer Periodo Intermedio y la xxi Dinastía, 1070-945 a.C. En segundo lugar, la protección de las uńas para prevenir su pérdida cuando se sumergían en baños de sal, los cuales eran sustituidos en Tenerife con el agua del mar o por su exposición a la brisa marina. Como tercera similitud, la posición de las manos sobre la zona púbica, recuperado en Egipto durante la XXI dinastía, que se había perdido desde Tutmosis II en la dinastía XviII, 1482-1479 a.C., hasta el final de la dinastía $\mathrm{xx}^{106}$. Esta relación con Egipto también es reconocida por Brothwell et al. ${ }^{107}$ y Llagostera ${ }^{108}$. No obstante, una práctica egipcia importante durante la XXI dinastía, la extracción de los órganos y su posterior recolocación dentro del cuerpo de la momia, no depositándolos ya en los jarros canopos, no se documentó (figs. 11a-11c).

Un segundo análisis aporta nuevos datos interesantes. Lo primero es la presencia de una incisión, posteriormente cosida, en el lado derecho del vientre, para facilitar el proceso de embalsamamiento ${ }^{109}$. Este hecho lo mencionan en el siglo XVII: "Le abrían por un costado y le sacauan las tripas y las partes que reciben corrupción, y luego todos aquellos güecos y vacíos los llenauan de manteca y voluían a coser muy sutilmente las partes abiertas $»^{10}$.

En segundo lugar, la identificación de antracosis después del análisis de los tejidos de la pleura al exterior de los pulmones y en los propios pulmones ${ }^{111}$. Por otra parte, el examen radiológico, poco preciso en el primer estudio, muestra que en la zona pélvica se ha introducido un relleno inorgánico ${ }^{112}$, quizás parecido al que conocemos en la momia en Madrid.

La momia fue reexaminada por Tomografía Computerizada en 1999 por Joann Fletcher en el hospital de Cambridge y fue objeto de una datación de la que se obtuvo un 1300 d.C., sin calibrar, pues sólo tenía 650 años (Fletcher, 2011), lo que confirma su clara proximidad cronológica con la momia de Madrid. Si la cronología reciente de ambas, siglos XII-XIII d.C., puede explicar en parte su buena conservación, el distinto tratamiento entre las momias de Cambridge y Madrid sugiere

\footnotetext{
104 Dawson, W.R., opus cit., n. ${ }^{\circ}$ 99, pp. 840, 834 fig. 3a-3b.

105 Dawson, W.R., opus cit., n. ${ }^{\circ} 99$, p. 839.

106 Dawson, W.R., opus cit., n. ${ }^{\circ}$ 99, pp. 851-853.

107 Brothwell, D.R., Sandison, A.T. y Gray, P.H.K., opus cit., n. ${ }^{\circ}$ 101, p. 346

108 Llagostera Cuenca, E., opus cit., n. ${ }^{\circ}$ 73, p. 41.

109 Brothwell, D.R., Sandison, A.T. y Gray, P.H.K., opus cit., n. ${ }^{\circ}$ 101, p. 339 fig. 5.

${ }^{110}$ López de Ulloa, F., opus cit., n. ${ }^{\circ} 10$, p. 316.

111 Brothwell, D.R., Sandison, A.T. y Gray, P.H.K., opus cit., n. ${ }^{\circ}$ 95, pp. 340, 342 fig. 7d.

112 Brothwell, D.R., Sandison, A.T. y Gray, P.H.K., opus cit., n. ${ }^{\circ}$ 95, p. 345 fig. 9.
} 


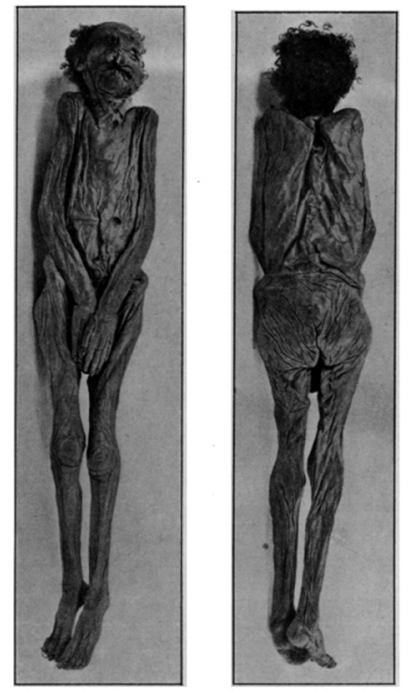

Fig. 11a. Momia masculina (1772) del University Museum of Archaeology and Ethnology, Cambridge (Dawson, 1927: 29 fig. 1-2).

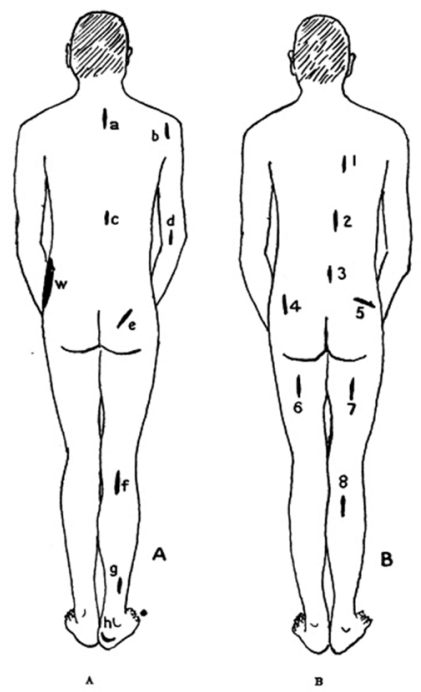

Fig. 11b. Incisiones en la espalda y piernas para introducir relleno en el cuerpo: a) momia de la

Dinastía XXI egipcia. b). momia guanche de Cambridge (Dawson, 1927: 30 fig. 3).

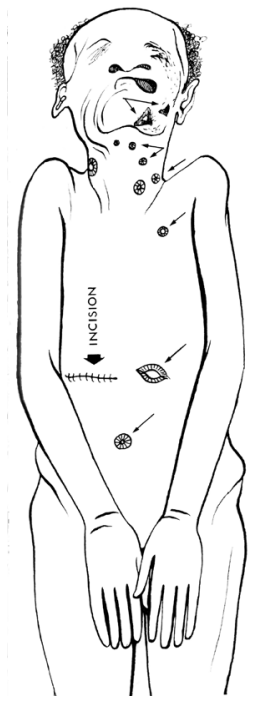

Fig. 11c. Incisión abdominal en la momia guanche de Cambridge (Brotwell et al., 1969: 339 fig. 5).

que la calidad de la momificación podía cambiar dependiendo de su procedencia social como sugieren las fuentes.

\section{LA MOMIA DEL BRITISH MUSEUM (1772)}

En la referencia de Viera y Clavijo había una parte de verdad sobre la entonces reciente presencia de una momia de Tenerife en el Museo Británico. Esta séptima momia fue donada en 1774 por el doctor John Coakley Lettsom, fundador un año antes de la Medical Society of London (BM Af 1774.0318.1), por lo que quizás el capitán Young de la fragata Weesel trajese más de una momia al Reino Unido. Por la información que nos proporciona el propio Lettsom ${ }^{113}$ se precisa que la momia donada la había sido adquirida unos cinco ańos antes, lo que nos lleva hacia 1772 o 1773, que la presentó «al Museo Británico, y la otra está ahora en mi posesión» (fig. 12). 


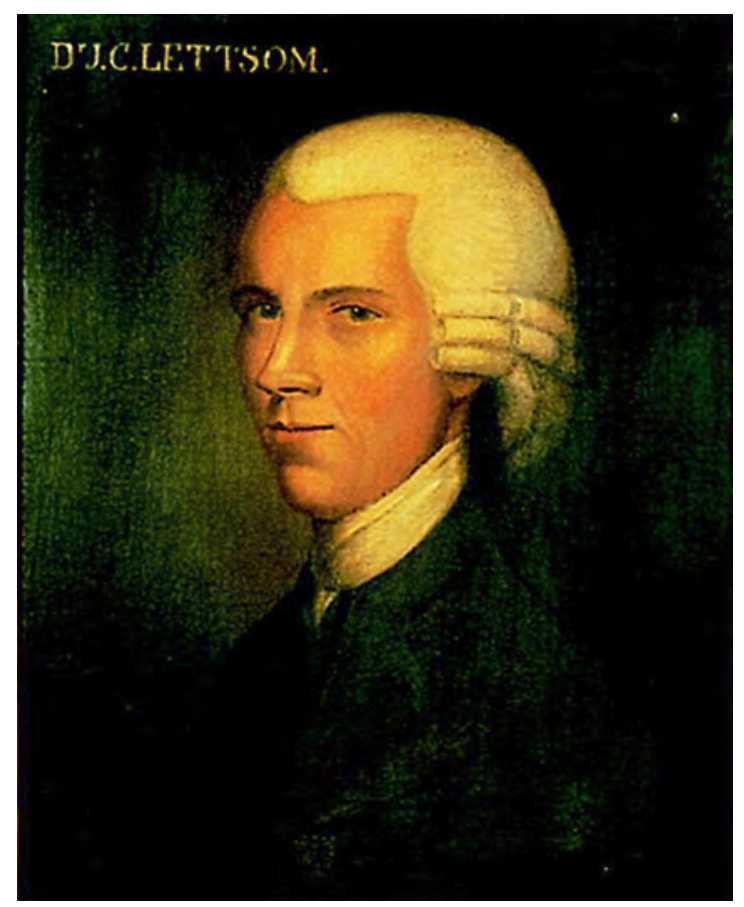

Fig. 12. Retrato de doctor John Coakley Lettsom ca. 1770 , por T.R. Poole (1809).

Royal College of Physician of London.

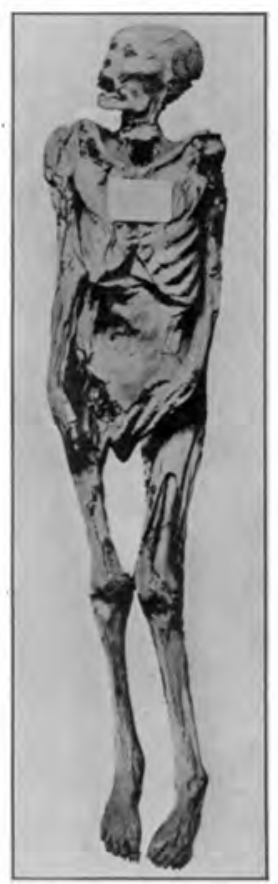

Fig. 13. Momia masculina (1772) del British Museum, actualmente convertida en un esqueleto (Dawson, 1927: 31 fig. 4).

Esta momia masculina, con unas dimensiones de $1,524 \mathrm{~m}$, fue transferida desde el Museo Británico al Museo del Real Colegio de Cirujanos, mientras que la mujer, de 1,498 m, que era propiedad de Lettsom, pasó a propiedad del cirujano Thomas Joseph Pettigrew ${ }^{114}$, experto en la realización de autopsias a momias egip$\operatorname{cias}^{115}$ (fig. 13).

La momia del Royal College of Surgeons lamentablemente fue convertida en un esqueleto, al igual que otras momias de Australia y del estrecho de Torres que separa Australia de Nueva Guinea, mientras se indica que se había perdido el rastro a la momia que había sido propiedad de Lettsom y después de Pettigrew ${ }^{116}$.

114 Pettigrew, T.J., opus cit., n. ${ }^{\circ}$ 61, pp. 234, 237.

115 Dawson, W.R. (1934): «Pettigrew's Demonstrations upon Mummies. A Chapter in the History of Egyptology». Journal of Egyptian Archaeology, 20, pp. 170-182.

116 Dawson, W.R., opus cit., n. ${ }^{\circ}$ 99, pp. 836, 835 fig. 4-5. 


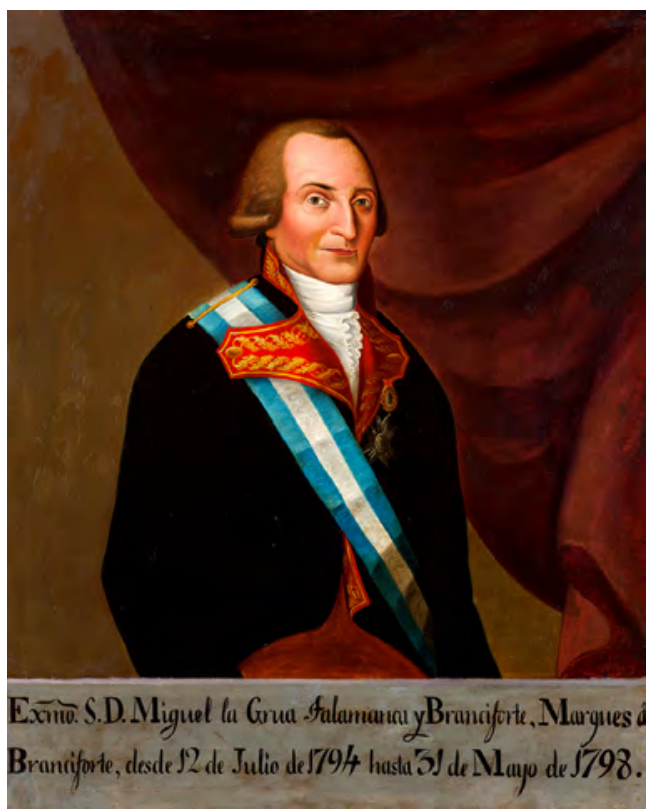

Fig. 14. Retrato de Miguel de la Grúa Talamanca, marqués de Branciforte, por José María Vázquez (1795). Sala capitular del Ayuntamiento de la ciudad de México.

\section{UNA MOMIA MASCULINA EN CAMINO HACIA EL SENEGAL (1785)}

Durante el viaje del futuro coronel Sylvain Meinrad Xavier de Golbéry desde Francia en 1785 hacia el Senegal por orden de Luis XVI, hizo una escala en Tenerife, donde trató de conseguir una momia guanche. La expedición se prolongó hasta 1787 y puesto que la escala fue al inicio del viaje no sabemos si realmente la momia masculina que se le entregón ${ }^{17}$ se conservó hasta su regreso a Francia. La mención de que el siciliano Miguel de la Grúa Talamanca de Carini, primer marqués de Branciforte, y futuro cuñado de Manuel Godoy, pues se casó en 1790 con su hermana (era entonces gobernador general de Canarias desde el 12 de junio de 1784 hasta 1788), disponía de varias momias que podría sugerir que la cueva del barranco de Erques seguía proporcionando nuevas momias (fig. 14).

117 Golbéry, F.J. (1802): Fragments d'un Voyage en Afrique fait pendant les années 1785, 1786 et 1787, dans les Contrées occidentales de ce Continent, comprises entre le cap Blanc de Barbarie... et le cap de Palmes. Paris, p. 94. 
«Todavía existen [...] en Tenerife, varias de esas cuevas donde los antiguos guanches depositaban los cuerpos embalsamados. Hay una cerca de Güímar y otra entre el Pico y Candelaria; y en estas cuevas aún se encuentran momias situadas de pie en sus nichos [...]. En estas cuevas los guanches hacían diferentes pisos, con nichos lo suficientemente profundos y altos como para situar a sus momias de pie en ellos. En la época de nuestra escala en Tenerife, el gobernador general de las Islas Canarias era el marqués de Branciforte, capitán general, chambelán y uno de los capitanes de las guardias del buen rey Don Carlos [IV] [...] El marqués de Branciforte puso a mi disposición una momia guanche, que tuve la libertad de elegir entre varias otras; mi elección recayó en la de un hombre.

Desde el cráneo hasta la parte baja del talón, la momia tenía cinco pies y diez pulgadas. Las facciones del rostro eran todavía visibles. Los cabellos eran negros, muy largos y bien conservados. Sin embargo, se desprendían fácilmente de la cabeza. Los maxilares estaban provistos de treinta y dos dientes, tan bien fijados en sus alvéolos que no se podían sacar sino con esfuerzos y por medio de un instrumento. La piel, bien conservada en todo el cuerpo, estaba seca aunque flexible; su color era de un moreno oscuro; la espalda y el pecho estaban cubiertos de pelo. El vientre y el pecho se hallaban llenos de cascarillas de semilla, blancas y ligeras, de un tamańo aproximado a los granos de arroz. Esta momia estaba envuelta y ceñida, como un niño en un pañal, en tres vueltas de bandas largas, hechas de piel curtida de macho cabrío o de cabra, de tres pulgadas y algunas líneas» ${ }^{118}$.

\section{CONCLUSIONES}

El conocimiento aproximado de un lugar con posibles momias en la isla de Tenerife se mantuvo después de la conquista, pues existía en la toponimia local de Fasnia el barranco de los Muertos, relativamente próximo a las poblaciones de Güímar a $15,7 \mathrm{~km}$, y Candelaria, a $27 \mathrm{~km}$. En su entorno se hicieron las primeras visitas a cuevas con momias por el comerciante inglés Thomas Nichols, $c a$. 1558, quien menciona por primera vez la presencia de una cueva con 300 cadáveres después de haber salido de Candelaria. Por otra parte, empezaban a circular momias descubiertas ocasionalmente, algunas saliendo incluso de Tenerife, pues Purchas vio dos cuerpos en Londres hacia 1613 y López de Ulloa otra en las islas en 1644.

La segunda persona que sabemos que accedió quizás a esta misma cueva fue el médico galés Evan Pieugh, quien en 1646, partiendo de Güímar, pudo visitar de nuevo una o varias de estas cuevas con 300 o 400 cuerpos, pues le mencionaron que había unas 20 cuevas con momias.

La primera referencia específica sobre un descubrimiento de momias se produjo en 1752 cuando se localizó en el acantilado de Martiánez del Puerto de la

118 GolbÉRY, F.J. (1998 [1802]): Fragmentos de un viaje a África. M. Hernández González y J.A. Delgado (eds.). La Laguna-La Orotava, pp. 140-141. 
Cruz una o dos momias que fueron llevadas para enseńarlas al Puerto de la Cruz y La Orotava. De este descubrimiento tuvo conocimiento el marino y comerciante George Glas, que en 1761 encargó a varios naturales la localización de una momia, aunque sólo encontraron fragmentos momificados, incluyendo una cabeza que conservaba el pelo, probablemente también en la zona del acantilado de Martiánez.

Antes del verano de 1764 se produjo probablemente una nueva visita a la cueva del barranco de Erques por Luis Román Jovel, capitán de infantería del regimiento provincial de Güímar y regidor de Tenerife, saliendo desde Güímar. A diferencia de otras visitas previas, se debieron extraer momias en esa ocasión, según Anchieta cuatro, pero probablemente fueron más o volvieron unos meses o pocos años después. Una momia pasó a la colección del regidor Gabriel Román Manrique de Lara, otra se la llevó a la península Lorenzo Vázquez Mondragón, responsable de la renta del tabaco hasta 1764, y la mejor se envió al regidor Francisco Machado Fiesco, cuñado de Gabriel Román, diputado general por las Islas Canarias en la Corte desde 1757, quien se tuvo que ausentar a Nueva Espańa entre 1765-1772, por lo que decidió ceder la momia a la colección de la Real Biblioteca como regalo al rey en 1766. Esta momia masculina fue trasladada con motivo de la apertura del Real Gabinete de Historia Natural y su Sala de Antigüedades en 1776.

Sin noticias de nuevos descubrimientos, en 1772 parece que salieron cuatro momias de la isla, de las que al menos una que se envió al Gabinete de Historia Natural del Jardín de Plantas del rey Luis XVI en París se asocia por Anchieta y por Quesada a este grupo del barranco de Herques, quizás extraídas de la cueva en una segunda ocasión. La cuestión es que a París parece que llegaron dos momias a través del conde de Chastenet, una de ellas femenina, aunque la segunda podría haberlo hecho posteriormente, en 1776, y explicaría que Berthelot se la atribuya a Borda, que dirigía la expedición, en la que también participaba el conde de Chastenet. En segundo lugar, la referencia de Quesada sobre que las momias del barranco de Erques «fueron a varios Reinos» sugiere que no sólo llegaron a Francia. En este sentido, también en 1772 llegaron a Londres con el capitán Young al menos dos momias, una masculina que Lord Sandwich, chancellor de la Universidad de Cambridge, donó a la biblioteca del Trinity College en 1773, mientras que la segunda pasó a ser propiedad del doctor John Coakley Lettsom, quien la donó en 1774 al Museo Británico, sin descartar que hubiese una tercera que se habría quedado el propio doctor Lettsom.

Avanzado 1777 o inicios de 1778 se debió encargar a Luis Arguedas y Brugieros, de la Real Compañía de Guardiamarinas, que había participado en la expedición de caballero Borda en 1776, conseguir una segunda momia femenina para el Real Gabinete de Historia Natural, que se remitió a Madrid, donde llegó en junio de 1778 con la cabeza separada del cuerpo después de un complicado viaje por mar.

No cabe descartar que esta segunda búsqueda de una momia para el Real Gabinete llevase a que se recuperaran más momias de la misma cueva del barranco de Erques, pues seguimos sin tener referencias a nuevos hallazgos, aunque tampoco cabe descartarlo. El hecho de que el marqués de Branciforte, gobernador general de Canarias, dispusiese de varias momias en 1785, ofreciéndole una masculina al marino francés Sylvain Meinrad Xavier de Golbéry, sugiere que se habían extraído más momias de la cueva. 
Cuatro décadas después, el agrónomo norteamericano Daniel Jay Browne, partiendo de Candelaria, volvió a visitar la cueva del barranco de Erques en septiembre de 1833, e indica que la cueva ya no tenía momias en su interior. No obstante, sí señala: «Tuve también ocasión de otras cuevas en las cercanías de este barranco, que guardaban cantidades de huesos sin embalsamar. Muchos se encontraban en perfecto estado de conservación pero yacían amontonados en un amasijo tal que no se hubiera podido armar un solo esqueleto ${ }^{119}$.

ReCiBido: 20-1-2020; ACEPTADO: 11-06-2020

119 Browne, D.J., opus cit., n. ${ }^{\circ}$ 53, pp. 101-102. 


\section{BIBLIOGRAFÍA}

Alfaro, C., Marcos, C. y Otero, P. (1999): «El Gabinete Numismático: 1711-1999». Tesoros del Gabinete Numismático: las 100 mejores piezas del monetario del Museo Arqueológico Nacional. Ministerio de Educación, Cultura y Deporte. Madrid, pp. 13-49.

Álvarez Rixo, J.A. (1845-79/1990): Apuntes sobre restos de los guanches encontrados en el siglo actual. En A. Tejera (ed.): «Apuntes sobre restos de los guanches encontrados en el siglo actual, de José Agustín Álvarez Rixo». Eres (Arqueología), 1 (1), pp. 121-134.

Álvarez Sosa, M. y Morfini, I. (2014): Tierras de Momias. La técnica de eternizar en Egipto y Canarias. Ediciones adAegyptum-Le Canarien. La Orotava, Tenerife.

Anchieta y Alarcón, J. de (1722-67/2011): Diario. I-II. En D. García Pulido (ed.). Ediciones Idea. Tenerife.

Anchieta y Alarcón, J. De (1735-67/2017): Cuaderno de citas. I-V. En D. García Pulido (ed.). Ediciones Idea. Tenerife.

Berthelot, S. (1840-42): Histoire Naturelle des Illes Canaries. Tome I. Partie 1. Ethnographie. Annales de la Conquête. Béthune et Plon. Paris.

Berthelot, S. (1840-42/1978): Etnografía y Anales de la Conquista de las Islas Canarias. Goya. Tenerife.

Béthencourt Alfonso, J. (1912/1994): Historia del Pueblo Guanche. II. Etnografía y Organización socio-politica. M.A. Fariña (ed.). Francisco Lemus editor. La Laguna.

Brothwell, D.R., Sandison, A.T. y Gray, P.H.K. (1969): «Human Biological Observations on a Guanche Mummy with Anthracosis». American Journal of Physical Anthropology, 30 (3), pp. 333-348.

Bory de Saint-Vincent, J.B.G.M. (1803): Essais sur les Isles Fortunées et l'antique Atlantide, o Précis de l'Histoire générale de l'Archipel des Canaries. Baudouin. Paris.

Bory de Saint-Vincent, J.B.G.M. (1803/1988): Ensayo sobre las Islas Afortunadas y la antigua Atlántida o compendio de la Historia General del Archipiélago Canario. A través del tiempo, 4. Ediciones J.A.D.L. La Orotava-Tenerife.

Browne, D.J. (1834/2005): Cartas desde las Islas Canarias. J.J. Cruz y M. Hernández González (eds.). Centro de la Cultura Popular Canaria.Tenerife-La Laguna.

Calatayud Arinero, M. ${ }^{a}$ A. (1987): Catálogo de documentos del Real Gabinete de Historia Natural (1752-1786). Fondos del Archivo del Museo Nacional de Ciencias Naturales. Consejo Superior de Investigaciones Científicas. Madrid.

Calatayud Arinero, M. ${ }^{a}$ A. (1988): Pedro Franco Dávila y el Real Gabinete de Historia Natural. Consejo Superior de Investigaciones Científicas. Madrid.

Cioranescu, A. (1963): Thomas Nichols. Mercader de azúcar, hispanista y hereje. Fontes Rerum Canariarum, XIx. Instituto de Estudios Canarios. La Laguna, pp. 9-92.

Daubenton, L.J.M. (1782): Encyclopédie Méthodique: Histoire Naturelle des Animaux. I. Panckoucke Librairie. Paris.

DAvies, R. (ed.) (1863): The Life of Marmaduke Rawdon of York or Marmaduke Rawdon, the Second of that Name. The Camden Society. London.

Dávila Ruiz de Eguino, P.F. (1767): Catalogue Systématique et Raisonné des Curiosités de la Nature et de l'Art qui composent le Cabinet de Monsieur Davila. Jean-Baptista-Louis de Rome de Lisle (ed.). I-III. Briasson. Paris. 
Dawson, W.R. (1927): "Contributions to the History of Mummification». Proceedings of the Royal Society of Medicine, 20, pp. 832-854.

Dawson, W.R. (1934): «Pettigrew's Demonstrations upon Mummies. A Chapter in the History of Egyptology». Journal of Egyptian Archaeology, 20, pp. 170-182.

Diego Cuscoy, L. (1968): Los Guanches. Vida y cultura del primitivo habitante de Tenerife. Publicaciones del Museo Arqueológico de Tenerife, 7. Tenerife.

Espinosa, A. (1970): Don José Clavijo y Fajardo. Cabildo Insular de Gran Canaria. Las Palmas de Gran Canaria.

Feller, F.X. De y Pérennes, M. (1833-34): Biographie universelle ou Dictionnaire historique contenant la nécrologie des hommes célèbres. X. Gauthier Frères et Cie. Paris.

Fernández de Béthencourt, F. (1878-86/1952): Nobiliario de Canarias. I-II. J. Regulo. La Laguna.

Fraga González, C. (1983): Escultura y pintura de José Rodríguez de la Oliva (1695-1777). Ayuntamiento de La Laguna. Tenerife.

Frutuoso, G. (1584-90/1939): Saudades da Terra. Livro I. En M.V. Arruda (ed.). Ponta Delgada. Açores.

Frutuoso, G. (1584-90/1964): Saudades da Terra. En E. Serra Ràfols, J. Régulo y S. Pestana (eds.): Las Islas Canarias de 'Saudades da Terra'. Fontes Rerum Canariarum, 12. Instituto de Estudios Canarios. La Laguna.

Fundación y estatutos de la librería pública de el rey $N S$ don Phelipe (1716). Oficina de Francisco de el Hierro. Madrid.

Glas, G. (1764): The History of the Discovery and Conquest of the Canary Islands: Translated from a Spanish Manuscript, lately found in the Island of Palma. With an Enquiry into the Origin of the Ancient Inhabitants. To which is added, A Description of the Canary Islands, including The Modern History of the Inhabitants, And an Account of their Manners, Customs, Trade, etc. R. and J. Dodsley \& T. Durham. London.

Glas, G. (1764/1982): Descripción de las Islas Canarias 1764. C. Aznar (ed.). Fontes Rerum Canariarum, 20. Instituto de Estudios Canarios. La Laguna.

Glas, G. (1764/2010): La Historia del Descubrimiento y de la Conquista de las Islas Canarias: Traducida de un Manuscrito Español, recientemente descubierto en la Isla de La Palma. Con un Informe sobre el Origen de los Antiguos Habitantes-1764-. P.N. Leal Cruz (ed.). Servigraf. La Laguna.

Golbéry, F.J. (1802): Fragments d'un Voyage en Afrique fait pendant les années 1785, 1786 et 1787, dans les Contrées occidentales de ce Continent, comprises entre le cap Blanc de Barbarie... et le cap de Palmes. Treuttel et Würtz. Paris.

Golbéry, F.J. (1802/1998): Fragmentos de un viaje a África. M. Hernández González y J.A. Delgado (eds.). A través del tiempo, 16. Ediciones J.A.D.L. La Laguna-La Orotava, pp. 133-143.

Gómez Escudero, P. (1639-1700/1978): Libro Segundo. Prosigue la conquista de Canaria. En F. Morales Padrón (ed.): Canarias: crónicas de su conquista. Ayuntamiento de Las Palmas-Museo Canario. Sevilla-Las Palmas, pp. 383-468.

Gómez Espinosa, T., Carrascoso, J. y Badillo, S. (2018): «La momia guanche del Museo Arqueológico Nacional. De las fuentes históricas a la tomografía computerizada». Boletín del Museo Arqueológico Nacional, 37, pp. 453-470.

Guerra Cabrera, J.C. (1994): Biografía de Marmaduke Rawdon. Un Mercader Inglés en Tenerife en el siglo XVII. Aula de Cultura. Cabildo de Tenerife. Tenerife. 
Guerra y Peña, L.A. De la (1760-91/2002): Memorias. Tenerife en la segunda mitad del siglo XVIII. E. Roméu Palazuelos (ed.). Ínsulas de la Fortuna, 7. Cabildo de Gran Canaria. MadridLas Palmas.

Guimerá Peraza, M. (1997): «El ilustrado hacendista Francisco Javier Machado Fiesco (17301808)». Anuario de Estudios Atlánticos, 43, pp. 211-311.

Hedges, R.E.M., Housley, R.A., Bronk, C.R. y van Klinken, G.J. (1992): «Radiocarbon dates from the Oxford AMS system: Archaeometry datelist 14». Archaeometry, 34 (1), pp. 141-159.

LetTsom, J.C. (1778): History of the Origin of Medicine. J. Phillips. London.

Llagostera Cuenca, E. (1993): «Estudio antropológico de la momia guanche Madrid-I». Boletín de la Asociación Española de Orientalistas, 29, pp. 37-42.

López de UlloA, F. (1646/1978): Historia de la conquista de las siete yslas de Canarias. En F. Morales Padrón (ed.): Canarias: crónicas de su conquista. Ayuntamiento de Las Palmas-Museo Canario. Sevilla-Las Palmas, pp. 259-342.

Lorenzo Lima, J.A. (ed.) (2018): Vecinos de la ciudad. Retratos en San Cristóbal de La Laguna (siglos XVI-XIX). Catálogo de exposición (octubre-diciembre, 2018) Ayuntamiento de San Cristóbal de La Laguna. La Laguna.

Luca López, F.P. DE (2011): «En relación a la Cueva de las Mil Momias». El Día/La Prensa, Santa Cruz de Tenerife, 5 de febrero de 2011, pp. 1-3.

Luxán, S. y Solbes, S. (2000): «El funcionamiento del estanco del tabaco en Canarias y en Navarra (1730-1780): un ejercicio de historia comparada». XIII Coloquio de Historia CanarioAmericana (Las Palmas, 1998). Cabildo Insular de Gran Canaria. Madrid-Las Palmas, pp. 2003-2020.

Maicas, R. y Mederos, A. (2016): «Arqueología canaria en el Museo Arqueológico Nacional». Boletín del Museo Arqueológico Nacional, 34, pp. 441-452.

Mañueco Santurtún, C. (1993): «Antecedentes del Museo Arqueológico Nacional (1711-1867)». Boletin de la $A N A B A D, 43$ (3-4), pp. 11-36.

Mañueco Santurtún, C. (2004): «El Gabinete de Antigüedades y el Museo de Monedas de la Real Librería (1711-1759)». En E.M. a Santiago (ed.): La Real Biblioteca Pública, 1711-1760: de Felipe V a Fernando VI. Biblioteca Nacional. Madrid, pp. 301-316.

Marín de Cubas, T. (1694/1986): Historia de las siete islas de Canarias. En A. de Juan Casañas, M. ${ }^{a}$ Régulo y J. Cuenca (eds.). Real Sociedad Económica de Amigos del País. Las Palmas.

Mederos, A. y Escribano, G. (2008): «Prospección arqueológica del litoral del Menceyato de Taoro. Municipios de Los Realejos, Puerto de la Cruz y La Orotava (Tenerife)». Canarias Arqueológica (Eres), 16, pp. 91-130.

Méndez Rodríguez, D.M. (2014): Momias, xaxos y mirlados. Las narraciones sobre el embalsamamiento de los aborígenes de las Islas Canarias (1482-1803). Instituto de Estudios Canarios. Sevilla-La Laguna.

Monod, T. (1976): «Notes sur George Glas (1725-1765), fondateur de Port Hillsborough (Sahara marocain)». Anuario de Estudios Atlánticos, 22, pp. 409-517.

Mora Postigo, C. (1995): «Momias guanches en el Museo Nacional de Etnología». I Congreso Internacional de Estudios sobre Momias (Puerto de la Cruz, Tenerife, 1992). I. Museo Arqueológico y Etnográfico de Tenerife. Cabildo de Tenerife. La Laguna, pp. 267-271. 
Nichols, Th. (1583): A Pleasant description of the fortunate Ilandes, called the Ilands of Canaria, with their straunge fruits and commodities verie delectable to read to the praise of God. Thomas East. London.

Nichols, Th. (1583/1963): Descripción de las Islas Afortunadas. En A. Cioranescu (ed.): Thomas Nichols. Mercader de azúcar, hispanista y hereje. Fontes Rerum Canariarum, xIx. Instituto de Estudios Canarios. La Laguna.

Paz SÁnchez, M. de (2013): «Edición, introducción y notas». J. de Viera y Clavijo, Homenaje a Carlos III. Idea. Tenerife.

Paz SÁnchez, M. DE (2016): «Edición, introducción y notas». J. de Viera y Clavijo, Historia de Canaria. I. Idea. Tenerife.

Pettigrew, T.J. (1834): A history of Egyptian mummies, and an account of the worship and embalming of the sacred animals by the Egyptians; with remarks on the funeral ceremonies of different nations, and observations on the mummies of the Canary islands, of the Ancient Peruvians, Burman priests, etc. London.

Prevost, A.F. (1746-63): «Histoire générale des voyages ou Nouvelle collection de toutes les relations de voyages par mer et par terre qui ont été publiées jusqu'à present dans les différentes langues de toutes les nations connues touchant leur situation, leur étendue, leurs limites, leurs divisions, leur climat, leur terroir avec les noueurs et les usages des habitans, leur religion, leur gouvernement, leur arts et leur sciences, leur commerce et leur manufactures; pour former un système complet d'histoire et de géographie moderne, qui representera l'état actuel de toutes les nations». 16 vols. Didot. Paris.

Purchas, S. (1613): «Purchas his Pilgrimage or Relations of the World and the Relations of the World and the Religions Observed in all Ages and Places Discovered from the Creation unto this Present. In foure Partes. This First containeth a Theologicall and Geographicall Historie of Asia, Africa, and America, with the llands Adiacent. Declaring the Ancient Religions beford the Flovd, the Heathnish, Jewish, and Saracenicall in all Ages since, in those parts professed, with their seueral Opinions, Idols, Oracles, Temples, Prestes, Fasts, Feasts, Sacrifices, and Rites Religious: Their beginnings, Proceedings, Alterations, Seets, Orders and Sucessions. With briefe Descriptions of the Countries, Nations, States, Discoueries, Priuate and Publike Customes, and the most Remarkable Rarities of Nature, or Humane Industrie, in the same». William Stansby. London.

Quesada y Chaves, D. DE (1784/2007): Canaria Ilustrada y puente americano. En P. Fernández-Palomeque, C. Gómez-Pablos y R. Padrón (eds.). Instituto de Estudios Canarios. La Laguna.

Reglamento (1930): Reglamento de los Museos, Nacional de Ciencias Naturales, Antropológico y Jardin Botánico. Ministerio de Instrucción Pública y Bellas Artes, Establecimiento Tipográfico Huelves y Compañía. Madrid.

Rodríguez Delgado, O. (1978): «La investigación arqueológica en la zona de Agache». El Día, Santa Cruz de Tenerife, 18 de junio de 1978.

Rodríguez Delgado, O. (1994): Guia de la comarca de Agache (Güimar). Tagoror Cultural de Agache. Güímar.

Rodríguez Yanes, J.M. (2000): «George Glas y su prisión en Canarias (1764-1765), un asunto de estado». Revista de Historia Canaria, 182, pp. 177-197.

Sánchez Cabrero, B. y Gómez Espinosa, T. (2018): «Datación mediante carbono 14 de la momia guanche del Museo Arqueológico Nacional». Boletín del Museo Arqueológico Nacional, 37, pp. $471-478$. 
SÁnchez Gómez, L.A. (2008): «Antropologías para después de una guerra. Plenitud y declive de la obra antropológica de José Pérez de Barradas (1939-1952)». En E. de Carrera y A. Martín Flores (eds.): Arqueología. América. Antropología. José Pérez de Barradas 1897-1981. Catálogo de Exposición (Madrid, 2008). Museo de los Orígenes. Madrid, pp. 399-431.

SÁnchez Gómez, L.A. (2014): «El Museo Antropológico del doctor Velasco (anatomía de una obsesión)». Anales del Museo Nacional de Antropologia, 16, pp. 265-297.

Sanz y Chanas, G.M. (1788): Encyclopedia metódica. I. Historia Natural de los Animales. Antonio de Sancha. Madrid.

SEDEÑo, A. (1507-1640/1978): Brebe resumen y historia muy verdadera de la conquista de Canarias. En F. Morales Padrón (ed.): Canarias: crónicas de su conquista. Ayuntamiento de Las Palmas-Museo Canario. Sevilla-Las Palmas: 343-381.

Sprat, T. (1667/1959): History of the Royal Society. Relation of the Pico Teneriffe, receiv'd from some considerable Merchants and Men worthy of Credit, who went to the top of it. En J.I. Cope y H.W. Jones (eds.). Routledge and Kegan Paul-Washington University Studies. LondonSt. Louis, pp. 200-213.

Sprat, T. (1667/2006): «Relación del Pico de Tenerife, que se debe a unos estimables comerciantes y hombres dignos de crédito que subieron a la cima». F.J. Castillo (ed.): La isla del Pico en las relaciones de los primeros viajeros ingleses. Escala en Tenerife, 27. Ediciones Idea. Sevilla-Tenerife, pp. 75-90.

Tejera, A., Galloway, D., García Pulido, D. y Delgado, J.F. (2010): La Cueva de las Mil Momias. Ed. Herques. Tenerife.

Urtarte, S. de (1573-83/2000): El Valle de Güimar en el siglo XVI. Protocolos de Sancho de Urtarte. En M.A. Gómez Gómez (ed.). Ayuntamiento de Güímar. Tenerife.

Verdun de la Crenne, J.R.A., Borda, J.Ch. y Pingré, A.G. (1778): «Voyage fait par ordre du roi en 1771 et 1772 , en diverses parties de l'Europe, de l'Afrique et de l'Amérique; pour vérifier l'utilité de plusieurs méthodes et instruments servant a déterminer la latitude et la longitude, tant de vaisseau que des côtes, iles et écueils qu'on reconnait; suivi de recherches pour rectifier les cartes hydrographiques». Imprimerie Royale. 2 vols. Paris.

Viera y Clavijo, J. De (1776-83/1967-71): «Noticias de la Historia General de las Islas de Canaria. Contienen la Descripción geográfica de todas. Una idea del origen, carácter, usos y costumbres de sus antiguos habitantes: De los descubrimientos, y conquistas que sobre ellas hicieron los Europeos: De su Gobierno Eclesiástico, Político y Militar: Del establecimiento, y sucesión de su primera Nobleza: De sus Varones ilustres por dignidades, empleos, armas, letras, y santidad: De sus fabricas, producciones naturales, y comercio; con los principales sucesos de los ultimos siglos». En A. Cioranescu (ed.). Goya Ediciones. Tenerife.

Viera y Clavijo, J. De (1776-83/2016): Historia de Canarias. I.M. de Paz Sánchez (ed.). Idea. Tenerife.

Viera y Clavijo, J. De (1799-1810/1982): Diccionario de Historia Natural de las Islas Canarias. Índice alfabético descriptivo de sus tres reinos: animal, vegetal y mineral. En M. Alvar (ed.). Mancomunidad de Cabildos de Las Palmas. Madrid.

Wilde, W.R. (1840/2000): Viaje a Tenerife. 2. edición inglesa. M. Tejedor y C. Jahrbeck (eds.). Colección Viajeros. Tauro ediciones. Tenerife-Madrid. 
